\title{
Caste, religion, and mental health in India
}

\author{
Aashish Gupta $\quad$ Diane Coffey ${ }^{* *}$
}

May 20, 2020

\begin{abstract}
The relationship between mental health and social disadvantage in low and middle income countries is poorly understood. Our study contributes the first populationlevel analysis of mental health disparities in India, where the two marginalized groups that we study constitute a population larger than that of the United States. Applying two complementary empirical strategies to data on 10,125 adults interviewed by the World Health Organisation's Survey of Global Ageing and Adult Health (WHOSAGE), we document and standardize gaps in self-reported mental health between the dominant social group (higher caste Hindus) and two marginalized social groups (Scheduled Castes and Muslims). We find that differences in socioeconomic status cannot fully explain the large disparities in mental health that we document, especially for Muslims. Our results highlight the need for research to understand the causes and consequences of mental health disparities in India, and for policies to move beyond redistribution and address discrimination against Scheduled Castes and Muslims.
\end{abstract}

keywords: health disparities; mental health; social inequality; India; caste; religion

${ }^{*}$ We appreciate helpful suggestions from Mahtab Alam, Gurinder Azad, Amrut Bang, Courtney Boen, Karthik Rao Cavale, Vikrant Dadawala, Jean Drèze, Irma Elo, Sonal Gihara-Sharma, Michel Guillot, Payal Hathi, Yogesh Kalkonde, Reetika Khera, Sirus Joseph Libeiro, Becky Pettit, Megan Reed, Jason Schnittker, Kanika Sharma, Dean Spears, David Sorge, Nikkil Sudharsanan, Satyajit Somavanshi, Reeve Vanneman, Yana Vierboom, the anonymous reviewers, the editors, and from attendees at SEARCH Gadchiroli, Annual meeting of the Population Association of America, and the Ambedkar Jayanti Seminar at the University of Pennsylvania. This is a pre-print version. For the online printed version, please see https:/ / doi.org/10.1007/s11113-020-09585-9.

${ }^{\dagger}$ Population Studies Center \& Department of Sociology, University of Pennsylvania. Email:aashishg@sas.upenn.edu.

$\ddagger$ Population Research Center \& Department of Sociology, University of Texas, Austin and Indian Statistical Institute, Delhi Centre. Email: coffey@utexas.edu. Diane Coffey was supported in part by grant, P2CHD042849, Population Research Center, awarded to the Population Research Center at The University of Texas at Austin by the Eunice Kennedy Shriver National Institute of Child Health and Human Development. The content is solely the responsibility of the authors and does not necessarily represent the official views of the NIH. The NIH played no role in the preparation of the article, nor in the decision to submit it for publication. 


\section{Introduction}

A large, multi-disciplinary literature in social epidemiology, public health, and medical sociology has been concerned with documenting and understanding disparities in health by race, ethnicity, gender, socioeconomic status, and caste. Researchers studying the United States have quantified differences in a large number of health outcomes by racial and ethnic group. This literature also investigates the mechanisms that generate health disparities and points to policy responses (Kessler and Neighbors, 1986; Link and Phelan, 1995; Williams, 2012; Goosby et al., 2017). Researchers studying low and middle income countries have also shed light on racial and ethnic health disparities in these contexts, particularly in mortality (Wood and Lovell, 1992; Burgard and Treiman, 2006). Mental health, in contrast, is widely recognized to be under-researched relative to its disease burden in low and middle income societies (Demyttenaere et al., 2004). Where population-level data do permit researchers to investigate the magnitude and nature of mental health disparities in new contexts, such as in Jackson et al. (2010)'s study of psychological distress in South Africa, gaps in mental health between advantaged and marginalized groups are large.

We investigate population-level disparities in self-reported anxiety and depression among adults in India, by caste and religion. Although prior research has shown that, in India, caste and religion play an important role in many other health outcomes, including infant mortality (Guillot and Allendorf, 2010; Spears and Geruso, 2018; Ramaiah, 2015), child height (Coffey et al., 2019), and the use of health services (Baru et al., 2010), to our knowledge, no prior study has investigated disparities in mental health by social group using population-representative data in India.

In particular, we document and analyze gaps in these self-reported mental health indicators between higher caste Hindus, the dominant social group, and Scheduled Caste Hindus (sometimes called "untouchables" or Dalits), a marginalized group which comprises about $17 \%$ of India's population. We also study gaps in self-reported mental health 
between higher caste Hindus and Muslims. Muslims are a religious minority who constitute about $14 \%$ of India's population. We expect Scheduled Castes and Muslims to have worse mental health, on average, than higher caste Hindus, not because of anything inherent about their genetic backgrounds, or cultural or religious beliefs and practices, but because of their well-documented positions of social and economic disadvantage. We ask: a) are there disparities in self-reported mental health indicators between Muslims and higher Caste Hindus, and between Scheduled Castes and higher Caste Hindus? b) What is the magnitude of these disparities? c) To what extent can they be explained by disparities in socioeconomic status?

Examining these disparities is important for several reasons. First, the marginalized groups that we study, Scheduled Castes and Muslims, number 201 million and 172 million respectively. Together, they constitute a population greater than that of the United States. Therefore, studying mental health in these large populations furthers our understanding of the global burden of mental illness and the global burden of disease as well (Whiteford et al., 2013). Second, documenting these disparities in mental health contributes to an ongoing conversation about the extent and consequences of social disadvantage and discrimination in India. It adds a much-needed analysis of mental health outcomes to the literature on health inequalities in India. Third, we test insights from medical sociology and social epidemiology in a new, developing country context with well-defined social boundaries and a high burden of material disadvantage.

We use data from the World Health Organisation's Study of Global Ageing and Adult Health (SAGE) conducted in 6 large Indian states in 2007-08. The WHO-SAGE is representative of the adult population in these states, and collected information on mental health outcomes, social group, and socioeconomic status. Prior research has pointed to the difficulties of translating and verifying measures of mental health disorders in developing countries (Axinn et al., 2013; Jacob and Patel, 2014). Hence, we use broad, simple indicators of mental health: the extent to which a person has problems with feeling sad, 
low, or depressed; and the extent to which they have problems with worry or anxiety. These questions are common to most mental health scales. We also investigate whether these patterns hold with other measures of mental health available from the WHO-SAGE.

Because prior research on mental health often finds that richer, better educated people have better mental health (Link and Phelan, 1995), and because India's Scheduled Castes and Muslims are materially disadvantaged, we further estimate mental health gaps net of socioeconomic differences. The results of two different empirical strategies allow us to draw the same robust conclusion: even after accounting for differences in educational attainment and asset wealth, marginalized social groups have importantly worse mental health outcomes than higher caste Hindus.

In the section that follows, we present a conceptual framework and background to contextualize our approach and findings. We then present our data and approach, followed by our results. We conclude with a discussion of why these findings are important. In short, most efforts by the Indian government to address social disadvantage focus on directing resources to marginalized social groups; either in the form of affirmative action in universities and government jobs, or in the form prioritizing marginalized groups for government transfers, such as loans and grants for houses, household assets, or village infrastructure. These policies and programs, while valuable for the people who benefit from them, do little to address the underlying environment of discrimination that perpetuates inequality across the lifecourse, including disparities in health (Tadvi and Vemula, 2019; Thorat et al., 2007; Housen et al., 2017). Responses to health disparities should combine resource distribution to marginalized groups with stronger stances against violence and broader efforts to address discrimination.

\section{Conceptual framework \& background}

This research builds on prior work which documents and interprets health disparities among people from advantaged and marginalized social groups. A rich literature from 
the United States considers the extent to which health disparities between people of different races can be explained by differences in economic status and education (Williams et al., 2010; Geruso, 2012; Do et al., 2012). Before presenting our analysis of mental health disparities in India, we briefly present a conceptual framework based on this literature that helps us interpret our results.

There is considerable evidence that educational attainment and economic resources affect health (Elo and Preston, 1996). These relationships often motivate researchers interested in understanding health disparities to control for differences in economic status and education in their analyses. Disparities that remain after controlling for socioeconomic variables provide evidence that discrimination, whether structural, such as forms of discrimination related to the organization of health care or to neighborhood segregation, or interpersonal, such as violence or unfair treatment, also contributes to health disparities. In the case of mental health in particular, prior studies point to the stress generated by exposure to discrimination as an important reason for differences in mental health outcomes among people from different social groups (Noh et al., 1999; Williams et al., 1997).

Two observations about this framework are particularly relevant to our analysis. The first is that the causality between socioeconomic variables and health can run in both directions: poor health can also cause low socioeconomic status (Deaton, 2003). To the extent that this is true, standardization analyses like ours, which investigate how much of gaps in health can be explained by gaps in economic status and education, will provide an upper bound on the explanatory power of the socioeconomic variables included in the model (Geruso, 2012). Of course, to the extent that socioeconomic variables included in the analysis do not capture everything that is relevant about a person's socioeconomic status that is relevant for their health, the standardization will underestimate the extent to which economic status and education explain health disparities. The second observation that we wish to highlight is that, as Hummer (1996) and others have pointed out, even if differences in socioeconomic status do explain a particular racial or ethnic gap 
in health, this does not mean that discrimination is not an ultimate cause of the disparity: discrimination often causes differences in economic and educational outcomes, as well (Pager, Bonikowski, and Western, 2009). Nevertheless, from the perspective of a researcher or policy maker who seeks to understand whether redistribution of educational and economic resources can close health gaps, the finding that differences in socioeconomic status cannot entirely explain health disparities suggests the need for addressing the broader social environment as well as unequal material conditions.

\subsection{Social disadvantage, socioeconomic status, and mental health}

The literature on racial disparities in mental health provides relevant background for studies of how other forms of social disadvantage, such as caste and religion, contribute to mental health outcomes. The findings in this literature are nuanced (Earl, Williams, and Anglade, 2011): although some studies have found lower rates of psychiatric disorders among Black Americans (Breslau et al., 2006), many find that they report worse life satisfaction and less happiness than whites (Hughes and Thomas, 1998).

More recent analyses from NHANES suggest that Black Americans have slightly higher prevalence of depression than non-Hispanic Whites (Brody et al., 2018). There is also considerable evidence that experiencing or perceiving discrimination triggers stress responses and contributes to poor mental health (Myer et al., 2008). Kessler and Neighbors (1986) analyze community studies and find that race and socioeconomic status interact to predict psychological distress. Jackson et al. (2010), who study South Africa, find that socioeconomic differences do not entirely explain differences in distress between blacks and whites.

\subsection{Social inequality and mental health in India}

There are many forms of social inequality that may shape mental health in India; this study focuses on two major divisions - caste and religion. Caste, a system of social strat- 
ification with endogamous marriage and hereditary social status, divides Indians into a large number of groups and sub-groups, called jatis, each occupying varying levels of ritual purity, privilege, and social status (Vaid, 2014; Ambedkar, 1937). The lowest castes, which were considered "untouchable" because interaction with them was considered polluting, are together classified as the Scheduled Castes (SCs) by the Indian constitution. Scheduled Castes, who describe themselves as Dalit or "oppressed," comprise about $17 \%$ of the Indian population (Office of the Registrar General, 2011) and qualify for affirmative action in politics, government jobs, and university admissions. If India's 200 million SCs formed a separate country, they would be the 5th largest country in the world, with a population slightly larger than Brazil's.

With a population of over 170 million, Muslims are India's largest minority religious group; $14 \%$ of the Indian population is Muslim. India has the third largest population of Muslims in the world, after Indonesia and Pakistan. Indian Muslims face economic and social discrimination, and often have human development outcomes similar to those among Scheduled Castes, with far fewer legal protections (Prime Minister's High Level Committee, 2006). Compared to the Scheduled Castes, there are fewer government affirmative action programs for Muslims. Muslims in India have frequently suffered violence, and the rise of right-wing Hindu political parties has further marginalized and disenfranchised Indian Muslims (Ali, 2019; Fazal, 2020).

Comparative sociologists, starting from Marx and Weber, have noted similarities between caste and religious stratification in India, and other ascribed systems of stratification, such as race (Marx et al., 2007; Weber, 2000). Despite similarities, there are also important differences between these systems of social stratification. Whereas racial boundaries are typically considered to be based on phenotypic differences, caste differences are typically considered to be based on occupational segregation and rules of social interaction governed by rules about purity and pollution (Ambedkar, 1937; Vaid, 2014).

Although caste and religion are social group identities distinct from class, many stud- 
ies document the role of social disadvantage in reinforcing economic disparities in India (Deshpande, 2017), in shaping education and schooling achievement (Desai and Kulkarni, 2008), in influencing employment outcomes (Thorat and Neuman, 2012; Aggarwal et al., 2015), as well as physical health (Ramaiah, 2015; Vyas et al., 2019). These disparities persist inter-generationally (Azam and Bhatt, 2015). Evidence suggests that government programs and the legal system are more coercive when dealing with members of marginalized social groups (Gupta et al., 2019; Ahmad and Siddiqui, 2017; Bose and Dayal, 2018). Experiments have helped show that discrimination plays a role in determining these differences (Thorat and Attewell, 2007; Datta and Pathania, 2016; Deshpande and Spears, 2016). This discrimination likely adversely affect the mental health of SCs and Muslims over and above the effects they have on economic and educational status.

Data on the mental health is limited in India, and there are no direct estimates of prevalence of mental health conditions at the national level (Patel et al., 1999; Poongothai et al., 2009; Gururaj et al., 2016). Modeled estimates from the Global Burden of Disease approach show that in 2017 the prevalence of depressive and anxiety disorders was similar, with about 3.3\% of the Indian population having each (Sagar et al., 2020). A small number of studies, drawing on survey data or community samples, have examined links between social disadvantage and mental health, however (Jadhav and Jodhka, 2012). Ram et al. (2014) find that male-bias in households was associated with positive mental health among men and negative mental health among women. In a study in the city of Chennai, Poongothai et al. (2009) found that female gender, and lower socioeconomic status were associated with depression. Similar findings have been reported from the state of Goa in India (Patel et al., 1999). Ravi and Engler (2015) find that workfare programs reduced anxiety and stress in rural parts of the state of Andhra Pradesh. Housen et al. (2017) find in a study of the Kashmir valley that $41 \%$ of the population had probable depression, and that exposure to traumatic events was significantly associated with mental illness.

In terms of caste, Mathias et al. (2015) find higher levels of depression among peo- 
ple from lower castes compared to higher castes in Dehradun district of Uttarkhand, a state in north India. In a study of mothers who had a recent delivery in the state of Jharkhand, Prost et al. (2012) find that Scheduled Tribe and Scheduled Caste women had higher odds of having psychological stress when compared to higher-caste women. In Nepal, a country with a similar caste structure as India, Hawes et al. (2016) finds that Dalits are more likely to have depressive episodes when compared to higher caste Brahmins and Chhetris. Spears (2016) uses data from a survey conducted in villages in 13 districts of North India to document that Scheduled Castes report lower life satisfaction than people from other castes. Our study builds upon this literature by exploring both caste and religious differences in mental health, and by using population-level data for adults.

There is growing awareness among researchers of the importance of integrating the study of social inequality with the study of mental health in India. Several autobiographies and short stories by Scheduled Caste and Muslim authors explore links between experiences of marginalization, discrimination, violence, and mental health (Hasan and Asaduddin, 2000; Valmiki and Mukherjee, 2008; Pawar and Pinto, 2015). Initiatives to help those facing mental health problems because of discrimination or violence have involved both counseling (Kandukuri, 2018) and therapeutic support (Susewind, 2013). Following the suicides of students from marginalized social groups in Indian universities, journalistic accounts have also focused on the mental health impacts of discrimination in India's elite universities (Jeelani, 2012; Mondal, 2016; Satheesh, 2019). Recently, psychiatrist Sushrut Jadhav, and anthropologists David Mosse and Ned Dostaler have pointed out that "caste, mediated by gender and class among other things, affects millions of people and yet we know little about the mechanisms or experiences of social suffering involved" (Jadhav et al., 2016) [p. 2]. Our research brings the tools of population health to advancing this understanding. 


\section{Data \& Methods}

\subsection{Data}

We analyze the World Health Organization's SAGE (Survey of Global AGEing and Adult Health) data collected in India in 2007-08. SAGE surveys adult health, with a focus on older adults, and is unique among large-scale population surveys in India because it asks questions about mental health as well as about physical health. SAGE is representative of the adult population aged 18 and above in six states: Assam, Karnataka, Maharashtra, Rajasthan, Uttar Pradesh, and West Bengal. These states were selected from among Indian states with populations of more than five million based on their geographic region and level of economic and human development (World Health Organization, 2013). They are home to almost half of India's 1.3 billion people (Office of the Registrar General, 2011).

SAGE used a multi-stage process to select respondents in each state. In rural areas, a stratified random sample of villages was selected based on village population size with 28 households selected from each village. In urban areas, a stratified random sample of city wards was selected based on ward population size. Within selected wards, two census enumeration blocks were further selected, from which 33 households were selected. In both urban and rural areas, respondents were chosen from within households using a household roster and a Kish grid. The survey's response rate was $92.3 \%$, calculated as the number of completed and partial interviews, divided by the number of respondents contacted (World Health Organization, 2013).

SAGE collected detailed demographic data for each respondent, including sex, age, caste, and religion. It also collected information on whether respondents belonged to one of the Scheduled Tribes recognized by the Indian government's affirmative action programs. Scheduled Tribes, also called adivasis, primarily live in central and eastern India. With the exception of Assam, which has the smallest overall population of any of the states studied, SAGE was not conducted in places with a substantial Scheduled Tribe 
population. Consequently, only a small proportion of the overall SAGE sample identify as Scheduled Tribe. Like Scheduled Castes and Muslims, Scheduled Tribes are marginalized and often discriminated against (Xaxa, 2008). However, due to the small sample size, we do not include people from Scheduled Tribes in our analysis. However, when future data collection efforts permit it, it will be useful for researchers to investigate mental health disparities between Scheduled Tribes and other groups. Similarly, mental health disparities in a nationally representative sample of marginalized social groups would be helpful.

We note that SAGE's demographic data do not distinguish among the three broad subgroups within higher caste Hindus - Other Backward Classes (OBCs), Forward castes, and Brahmins. These three subgroups are hierarchically ranked in the order that they are listed here, with Brahmins having the highest social rank. The average educational and economic outcomes for these groups match their social ranking. The fact that we cannot distinguish among these groups is a limitation of the SAGE data because, although OBCs have not been as marginalized as Scheduled Castes, Scheduled Tribes, and Muslims, they have historically faced caste-based discrimination. As a result, affirmative action programs were expanded to include OBCs in the late 1990s. If we were able to remove OBCs from the group "higher caste Hindus," we would be able to document mental health gaps between marginalized groups and socially-privileged groups which would almost certainly be larger than the disparities between these marginalized groups and the group of higher caste Hindus that SAGE allows us to identify. Therefore, the magnitudes of the disparities that we document should be considered conservative.

Mental health outcomes. We use responses to two general, simply-worded questions about self-reported mental health as our outcomes of interest. SAGE asked respondents the following questions:

- "Overall in the last 30 days, how much of a problem did you have with feeling sad, low or depressed? None, mild, moderate, severe, or extreme?" 
- "Overall in the last 30 days, how much of a problem did you have with worry or anxiety? None, mild, moderate, severe, or extreme?"

These questions are common to most mental health screening tools (Diener et al., 1999). In additional analyses, we also test the robustness of our results using additional mental health related outcomes in the WHO-SAGE.

Independent variables. The independent variables we use in our analysis are age, sex of the respondent, household assets owned, education, per-capita log expenditure, rural residence, and state.

Income data is typically hard to collect in developing countries; asset wealth is a more reliable indicator of economic status (Filmer and Pritchett, 2001). We therefore use asset wealth as our primary indicator of economic status. SAGE asked respondents whether or not their household owns each of 17 assets: a chair; a table; a car; a motorcycle; a bicycle; a bullock cart; livestock; a clock; a bucket; a cot, a bed, or mattress; a refrigerator; a fixed line telephone; a mobile phone; a radio; a tape recorder, or cd player; and sewing machine. We created five asset ownership categories $(0-4,5-6,7-8,9-10$, more than 10) based roughly on quintiles of asset ownership among all the respondents in the sample. Similarly, we created five educational attainment categories (no education, 1-5 years, 6-8 years, 9-12 years, more than 12 years) based, roughly, on quintiles of educational attainment.

In addition to asset wealth and educational attainment, the results in this paper also control for the log of monthly household expenditure per capita, which is an estimate based on a respondent's answer to the question: "In general, what is your household's average overall monthly spending?"

\subsection{Approach}

We ask: how large are the gaps in self-reported mental health, and can the gaps between Scheduled Castes and higher caste Hindus, and between Muslims and higher caste Hindus, be explained by differences in their socioeconomic status? In order to answer these 
questions, we use two complementary empirical strategies. We first use a non-parametric reweighting standardization technique to generate counterfactual distributions of mental health outcomes among Scheduled Castes and Muslims. These distributions tell us what the mental health outcomes of the two marginalized groups would look like if they had the same distribution of educational attainment and asset wealth as higher caste Hindus. An advantage of this approach is that it matches on the full distribution of SES variables, not just the means, as regression would. It flexibly allows any non-parametric interaction between educational attainment and asset wealth. Second, we use parametric ordered logit regression to show that after controlling for SES differences, Scheduled Castes and Muslims have worse mental health. The advantage of this regression analysis over the non-parametric reweighting approach is that there are standard inference procedures that allow us to test the statistical significance of our results. We use survey weights throughout, and account for the mutli-stage sampling design of the survey by clustering our standard errors at the level of the primary sampling unit.

Non-parametric reweighting standardization. The reweighting standardization approach that we use to create counter-factual distributions of mental health outcomes for Scheduled Castes and Muslims is similar to the one used by DiNardo, Fortin, and Lemieux (1996) in their study of changes in the wage distribution in the United States. It has been used in health disparities research as well (Geruso, 2012; Coffey, 2015). The reweighting function that we use to produce the counter-factual distributions is defined as

$$
\Psi(\mathbf{x})=\frac{f(\mathbf{x} \mid g=1)}{f(\mathbf{x} \mid g=0)^{\prime}}
$$

where $\mathbf{x}$ is a single set of indicators for the intersections of the 5 educational attainment categories and 5 asset ownership categories described in Table 1. Reweighting is therefore done over 25 education by asset ownership bins. The function $f(x \mid g)$ is the empirical probability mass function for bin $x$ among the higher caste Hindu population $(g=1)$ or the Scheduled Caste or Muslim population $(g=0)$. In other words, $f(x \mid g)$ is the fraction 
of the population group $g$ sample in education by asset bin $x$, computed using survey sampling weights. The reweighting function $\Psi(\mathbf{x})$ is multiplied by the sampling weight of each Scheduled Caste or Muslim observation, so that a counterfactual distribution can be computed for a counterfactual Scheduled Caste or Muslim population that has educational attainment and asset ownership to match that of higher caste Hindus.

Therefore, the counterfactual reweighted distribution of mental health outcomes $m$ is

$$
\tilde{m}=\frac{\sum_{i} \Psi\left(\mathbf{x}_{\mathbf{i}}\right) w_{i} m_{i}}{\sum_{i} \Psi\left(\mathbf{x}_{\mathbf{i}}\right) w_{i}},
$$

where $m_{i}$ is the self-reported mental health outcome of person $i ; x_{i}$ is the education by asset bin of person $i$; and $w_{i}$ is the survey sampling weight of person $i$.

To provide some intuition for what the reweighting does, we note that because Muslims and Scheduled Castes have less education than higher caste Hindus, the reweighted distribution puts more weight on the mental health outcomes of more educated and wealthier Muslim and Scheduled Caste respondents than it does on the mental health outcomes of less educated and poorer respondents. The extent to which mental health outcomes in the counterfactual distributions improve relative to the unadjusted distributions can be interpreted as the extent to which mental health outcomes among Muslims and Scheduled Castes can be explained by their socioeconomic disadvantage relative to higher caste Hindus. Because disadvantage in socioeconomic status among marginalized groups (relative to higher-caste Hindus) can be seen across the distribution of SES, we are not concerned that the standardization is sensitive to the choice of the standard (Preston et al., 2000).

It is important to note that the non-parametric nature of this approach limits the number of SES variables that can be adjusted for: if the sample is partitioned into many bins, computing reweighted mental health outcomes for Scheduled Castes and Muslims would require dropping some of the higher caste Hindu respondents from the sample. This is because the denominator in equation 1 would be zero if there are higher caste Hindus who 
have no counterparts in the marginalized group. However, when we reweight over the 25 educational attainment $\times$ asset wealth bins, we do not need to drop any higher caste Hindu respondents from the sample. In the ordered logit regression approach, which we describe below, we control for household expenditure per capita as well as for asset wealth.

Parametric ordered logit regression. Each of the outcome variables we study is measured using five ordered categories (none, mild, moderate, severe, extreme). We model the ordered, discrete self-reported mental health outcome using a linear ordered logit regression model. Prior literature has used ordered logit models to study other disparities in ordered health outcomes, including disparities in self-reported health by sex and marital status (Gorman and Read, 2006; Zheng and Thomas, 2013).

In this model, a latent variable $m^{*}$ is assumed to be a linear function of the independent variables, with an error term with a logistic distribution. The ordered outcome categories correspond to cutpoints in the continuous distribution of $m^{*}$ that are unobservable parameters fit by maximum likelihood (Rodríguez, 2007).

We write the linear model for $m^{*}$ as

$$
\begin{aligned}
& m_{i j}^{*}=\beta_{1} \text { Muslim }_{i j}+\beta_{2} \text { Scheduled Caste }_{i j}+ \\
& \beta_{3} \text { female }_{i j}+\alpha_{i j}^{\text {age }}+E_{i j} \theta+A_{i j} \lambda+ \\
& \beta_{4} \log (\text { expenditure })_{i j}+\beta_{5} \log (\text { expenditure })_{i j}^{2}+\varepsilon_{i j},
\end{aligned}
$$

where $\varepsilon_{i j}$ has a logistic distribution and the ordered logit link function additionally includes four cut-points for the five levels of the outcome variable. Subscripts $i$ index respondents and subscripts $j$ index survey primary sampling units, which are villages or urban census enumeration blocks. The coefficients of interest are $\beta_{1}$, on Muslimij, and $\beta_{2}$, on Scheduled Caste $e_{i j}$. We also add controls in stages to see whether, in controlled specifications, the gap in mental health decreases, comparing Scheduled Castes and higher caste Hindus, and comparing Muslims and higher caste Hindus. female ${ }_{i j}$ is an indicator 
for whether person $i$ is female; $\alpha_{i j}^{a g e}$ is a set of dummy variables for the age of the respondent, in years; $E_{i j}$ is a set of five indicators for educational attainment; $A_{i j}$ is a set of five indicators for asset wealth; $\log (\text { expenditure })_{i j}$ and $\log (\text { expenditure })_{i j}^{2}$ are controls for $\log$ monthly household expenditure and log monthly household expenditure squared.

One disadvantage of the ordered logit approach is that it constrains the covariates to have the same linear latent effect on mental health at each cut point. For example, if the question is, "Overall, in the last 30 days, how much of a problem did you have with feeling sad, low, or depressed? None, mild, moderate, severe, or extreme?," and if the exponentiated coefficient on Scheduled Caste ${ }_{i j}$ is 2, that implies that Scheduled Castes have twice the odds of reporting both having an extreme problem relative to higher caste Hindus and of having an extreme or severe problem relative to higher caste Hindus. ${ }^{1}$ The non-parametric standardization technique helps us avoid this limitation. We also check that the results from the ordered logistic regressions are similar to the results from a logistic model with dichotomous outcomes.

The ordered logit has two main advantages over the non-parametric reweighting standardization technique described above. First, it is possible to include a much larger number of control variables. Second, unlike the reweighting standardization, inference here is straightforward: we can determine whether Muslims and Scheduled Castes have statistically significantly different self-reported mental health outcomes after controlling for relevant demographic and socioeconomic variables.

\footnotetext{
${ }^{1}$ We note that, because odds are ratios of probabilities, a uniform effect on odds could have different effects on probabilities that are low, moderate or high.
} 


\section{Results}

\subsection{Summary statistics}

Table 1 shows the proportion of people in each social group who reported having mild, moderate, severe, or extreme problems with depression and anxiety. ${ }^{2}$ Among the three social groups we study, about $43 \%$ reported experiencing sadness or depression in the last month, while $52 \%$ said that they experienced any anxiety.

\section{[Insert Table 1 approximately here.]}

For both outcomes, Scheduled Caste and Muslim respondents had worse mental health than higher caste Hindu respondents. About $41 \%$ of higher caste Hindu respondents, $46 \%$ of Scheduled Caste respondents, and 51\% of Muslim respondents reported being mildly, moderately, severely or extremely depressed in the last month. Slightly less than half of higher caste Hindu respondents, 57\% of Scheduled Caste respondents, and $60 \%$ of Muslim respondents reported facing anxiety in the last month.

Table 1 also reports summary statistics for the independent variables we use in our analysis. Higher caste Hindus, Scheduled Castes and Muslims have similar age and sex profiles: the average age is about 41 years and about $49 \%$ of respondents are female. The summary statistics in Table 1 show, as many other studies do, that Scheduled Castes and Muslims are poorer and have less education than higher caste Hindus. Schedule Castes are also more likely to live in rural areas than higher-caste Hindus, while Muslims are as likely to live in urban areas as higher-caste Hindus.

\subsection{Descriptive results}

The left-most bars of Figures 1 and 2 show distributions of self-reported depression (Figure 1) and self-reported anxiety (Figure 2) among disadvantaged groups. These distributions are produced using survey weights provided by the WHO SAGE. The middle

\footnotetext{
${ }^{2}$ These means and standard errors were calculated using the "mean" command in Stata with the "svy" prefix to account for survey design.
} 
bars of Figures 1 and 2 show distributions of the same variables for higher caste Hindus. Within each Figure, the distribution for higher caste Hindus is repeated in panels (a) and (b) in order to facilitate comparison with the disadvantaged groups. These distributions show that higher caste Hindus are more likely than both Dalits and Muslims to report better mental health responses. Differences between higher caste Hindus and disadvantaged groups exist across all categories of the responses; they are not driven by differential responses in just one category among the five possible responses.

\section{[Insert Figures 1 and 2 approximately here.]}

We performed non-parametric Mann-Whitney-Wilcoxon rank-sum tests to compare each distribution among a disadvantaged group to that of higher caste Hindus. The resulting $p$-values are not shown because for each of the four comparisons the resulting $p$-value is less than 0.001 . These tests allow us to reject the null hypotheses that the distributions of self-reported mental health outcomes among disadvantaged groups and higher caste Hindus are the same.

\subsection{Non-parametric reweighting standardization results}

The right-most bars of Figures 1 and 2 plot distributions of self-reported mental health that are reweighted using the non-parametric approach described above. The reweighted distributions represent counterfactual distributions of mental health outcomes that answer the question: what would the mental health outcomes of Muslims (or Scheduled Castes) look like if they had the same distribution of assets and educational attainment as higher caste Hindus?

The reweighted distributions are closer to the distributions of mental health outcomes among higher caste Hindus than the unweighted distributions, but for most outcomes, there is nevertheless still a visible mental health gap. The exception is the gap for depression between Scheduled Castes and higher caste Hindus, which appears to be entirely explained by differences in assets and educational attainment. 


\subsection{Parametric ordered logit results}

Table 2 reports proportional odds from the ordered logit regressions of depression and anxiety respectively on social group membership and control variables. In each panel, model 1 shows proportional odds of reporting worse mental health responses for Muslims, Scheduled Caste respondents, and women, with age dummies. The age dummies allow a non-linear relationship between mental health and the age of the respondent. Models 2 to 4 add controls for socioeconomic variables in stages: model 2 adds controls for education categories, model 3 adds controls for asset categories, and model 4 adds controls for per-capita log expenditure. Model 5 controls for state dummies and rural residence. [Insert Table 2 approximately here.]

Model 1, which has only demographic controls for age and sex, finds that Muslims have about 1.7 times the proportional odds of reporting depression, and 1.9 times the proportional odds of reporting anxiety, when compared to higher caste Hindus. After adding the full set of SES controls (model 4), the coefficient drops to 1.4 for depression and 1.5 for anxiety. These results suggest that Muslims' lower SES (as measured by the controls included in the regression) cannot account for the fact that they have worse mental health than high caste Hindus. The coefficient on being Muslim is robust to the inclusion of state of residence and rural residence (model 5).

Scheduled Castes have 1.4 times the proportional odds of reporting depression as higher caste Hindus, and 1.5 times the proportional odds of reporting anxiety (model 1). As the results of the reweighting standardization suggested, model 4 shows that the association between having depression and being Scheduled Caste is not statistically significant after controlling for SES (model 4 of Table 2). However, the association between anxiety and being Scheduled Caste remains statistically significant after controlling for SES, but not after controlling for state dummies and rural residence.

Tables A1 and A2 in the Appendix verify that the results presented in Table 2 are robust to the inclusion of interactions. The regressions in Tables A1 and A2 take the 
same form as Table 2, except that we add interactions between social group and asset category (A1), and interactions between social group and educational attainment category (A2). We find no evidence that social group interacts with socioeconomic status to predict mental health outcomes in this ordered logit framework. Figure A1 plots the relationship between asset ownership and the mental health outcomes we study, and education and the mental health outcomes we study, separately for each social group. These results suggest that higher socioeconomic status is associated with better mental health, but not differentially so for the three social groups.

\subsection{Additional analyses}

Are these results robust to modifications to the analytic approach or the particular mental health questions we study? Results shown in Tables A3, A4, and A5 in the Supplementary Appendix address this question.

Table A3 shows odd-ratios from logistic regressions for dichotomized self-reported mental health outcomes. Those who reported having no problems with depression or anxiety were classified as having no depression or anxiety, respectively. Those who reported having mild, moderate, severe, or extreme problems were classified as having the respective mental health problem. Models 1 and 2 in Table A3 are for depression or sadness, and models 3 and 4 are for anxiety or worry. Models 1 and 3 control only for sex and age. Models 2 and 4 also control for state, rural residence, assets, education, and expenditure. The results here are remarkably similar to the results in Table 2 which uses ordered logit regression.

Table A4 shows ten alternative mental health outcomes available from the WHOSAGE. For each outcome, we run two regressions: one with only age and sex controls, and one with all the controls specified in model 5 of Table 2 - age, sex, education, assets, expenditure, rural residence, and state. If the outcome has ordered responses, we use ordered logit models. For binary outcomes, we use logit models. The results shown in the 
Supplementary Appendix are similar to the main results. For some outcomes, Scheduled Castes and Muslims have significantly worse outcomes even after including all controls, and for some outcomes, they do not. However, they have higher odds of reporting mental health problems for every outcome. This shows that our results are not sensitive to the way the mental health questions we study are asked.

Table A5 shows that controlling for socioeconomic status by controlling for 17 assets as individual dummy variables (rather than five asset categories) does not change the results.

Tables A6 and A7 report the results of ordered logit regressions of mental health outcome on social group separately by state. Although the number of observations in regressions that are stratified by state is small, and therefore may not be powered to detect significant differences across social groups, we nevertheless find higher odds of reporting mental health problems among Muslim and Scheduled Caste respondents in most states. The state-wise patterns are interesting and revealing. In Assam, a state with a large Muslim population and a comparatively more violent and continuous history of riots against Muslims (Weiner, 1983; Pathak, 2012), Muslims are as much as 3.5 times more likely to have anxiety or depression than higher-caste Hindus. Disparities between Muslims and higher-caste Hindus are also high in Maharashtra and West-Bengal, where available data suggest a higher incidence of riots (Wilkinson, 2006). Disparities between Scheduled Castes and Higher-castes have less variation across states, suggesting that marginalization across states may be similarly severe (Teltumbde, 2007).

Supplementary Appendix Table A8 compares the SAGE sample to that of the nationally representative India Human Development Survey 2011 (Desai and Vanneman, 2015). Compared to the IHDS, the SAGE sample was older and poorer. Although the WHO-SAGE was not designed to generate nationally representative estimates for the social groups we study here, we note that the patterns of disadvantage in both the SAGE and the IHDS are similar. In both surveys, Scheduled Castes and Muslims are more likely 
to be disadvantaged when compared to higher caste Hindus, with Scheduled Castes being the most disadvantaged.

Figure A2 in the Supplementary Appendix shows mental health outcomes by social group and by age. The age pattern of mental health outcomes shown in Figure A2 is similar to the age pattern found in studies of mental health elsewhere in the world (Kessler and Bromet, 2013). Specifically, older people have worse mental health, on average, than younger people. Most importantly, the figure shows that across all ages, marginalized groups have worse mental health.

\section{Discussion}

Our research provides the first population-level evidence that Scheduled Castes and Muslims have worse self-reported mental health than higher caste Hindus. In most cases, these gaps remain even after accounting for the fact that Scheduled Castes and Muslims have less education and own fewer assets.

Additional data are needed to better understand the mechanisms and processes that generate the gaps that we document. The study of mental health disparities in the United States has benefited data sets which provide information not only on mental health outcomes, social group membership, and socioeconomic status, but also on experiences of discrimination, the extent to which discrimination is internalized, stressors, experiences of violence or trauma, childhood health and socioeconomic status, neighborhood-level variables, and, more recently, clinical measures of mental-health. Moving beyond selfreported measures of mental health to clinical diagnoses may provide additional insights.

If we are to learn exactly how caste and religion shape mental health outcomes in India, such variables will need to be added to existing health surveys and new surveys will need to be fielded. With the exception of a few studies which document how discrimination against Scheduled Castes is practiced (Shah et al., 2006; Jodhka, 2002; Coffey et al., 2018), there are few quantitative measures of experiences of discrimination by marginal- 
ized groups. Yet, there are many challenges to collecting such data in India. Perhaps understandably, considering India's high rates of mortality and burden of infectious and childhood disease, the government and international organizations have traditionally focused on collecting physical health data. However, given its large population burden as well as its links with social inequality, monitoring and improving mental health should also be a priority.

In this study, we are limited by data that represent six large states, but not all of India. Surveys that bring in evidence from other states, or are nationally representative are thus crucial. Nor do the SAGE data allow us to separate those belonging to Other Backward Classes and High Castes. Investigating disparities in mental health between High-Caste Hindus and Other Backward Classes is important as well. Finally, the data do not allow us to compare answers to the depression and anxiety questions we study to clinical diagnoses. Although such diagnoses would certainly be useful, researchers have pointed to the challenges of making them in contexts with few trained mental health professionals (Jacob and Patel, 2014).

Despite these limitations, our results, combined with prior research on social inequality in India, nevertheless point to the incompleteness of government efforts to address the consequences of social disadvantage. First, it is important to note that federallysponsored programs to reduce economic, educational, or health disparities between Hindus and Muslims are extremely limited. Rather than being assisted by the state, Muslims in India are often victims of politically motivated violence (Wilkinson, 2006; GhassemFachandi, 2012; Kamdar, 2020). The state arguably does more to promote the interests of Scheduled Castes. Affirmative action in the form of caste-based quotas for political office, higher education, and government jobs are provided for in the Indian constitution. Government development programs also often make Scheduled Caste priority beneficiaries; for example, in many states, a proportion of annual government budgetary allocations are required to be specially marked for Scheduled Castes under the Scheduled Caste Sub- 
plan.

Our results, however, suggest that merely redistributing wealth, and even helping Scheduled Castes or Muslims get more education, may not close gaps in mental health. Indeed, our results echo those of Coffey et al. (2019), who find that gaps in height between lower caste and higher caste children cannon be explained by observable characteristics (such as parental education and household economic status) alone. This may be because discrimination against Scheduled Castes is still widespread - even though a set of discriminatory practices known collectively as "untouchability" have been criminalized since the 1950s, these laws go largely unenforced. Surveys suggest that a large fraction of people still openly admit to engaging in these forms of discrimination (Thorat and Joshi, 2015; Coffey et al., 2018). To our knowledge, similar estimates of the extent to which people from dominant social groups admit to discrimination against Muslims have not yet been published. ${ }^{3}$

We hope that these results will contribute to broader efforts to draw attention to the need for research and policies to address social inequality in India. Further study of the relationships among discrimination, prejudice, and mental health in the context of social inequality and material disadvantage in India would inform social policy in India and, by testing external validity, theories of health and social inequality everywhere.

\footnotetext{
${ }^{3}$ Social Attitudes Research, India (SARI) is a mobile phone survey which collects data on social discrimination in India. In 2018, SARI asked about discrimination against Muslims in its Bihar, Jharkhand, and Maharashtra samples. The data, which are available at www.riceinstitute.org, are currently being analyzed.
} 


\section{References}

Aggarwal, Ankita, Jean Drèze, and Aashish Gupta. 2015. "Caste and the Power Elite in Allahabad." Economic E Political Weekly 50:45.

Ahmad, Irfan and Md Zakaria Siddiqui. 2017. "Democracy in Jail: Over-representation of minorities in Indian prisons." Economic $\mathcal{E}$ Political Weekly 52:98-106.

Ali, Asim. 2019. "What if this is the Hindu Rasthra?" The Wire .

Ambedkar, Bhimrao Ramji. 1937. Annihilation of caste: With a reply to Mahatama Gandhi. University of Columbia.

Axinn, William G, Dirgha J Ghimire, Nathalie E Williams, and Kate M Scott. 2013. “Gender, traumatic events, and mental health disorders in a rural Asian setting." Journal of Health and Social Behavior 54:444-461.

Azam, Mehtabul and Vipul Bhatt. 2015. "Like father, like son? Intergenerational educational mobility in India." Demography 52:1929-1959.

Baru, Rama, Arnab Acharya, Sanghmitra Acharya, AK Shiva Kumar, and K Nagaraj. 2010. "Inequities in access to health services in India: Caste, class and region." Economic and Political Weekly 45:49-58.

Bose, Ajoy and John Dayal. 2018. For Reasons of State: Delhi Under Emergency. Penguin Random House India Private Limited.

Breslau, Joshua, Sergio Aguilar-Gaxiola, Kenneth S Kendler, Maxwell Su, David Williams, and Ronald C Kessler. 2006. "Specifying race-ethnic differences in risk for psychiatric disorder in a USA national sample." Psychological Medicine 36:57-68.

Brody, Debra J, Laura A Pratt, and Jeffery P Hughes. 2018. "Prevalence of depression among adults aged 20 and over: United States, 2013 - 2016." Technical report, Centers for Disease Control and Prevention.

Burgard, Sarah A and Donald J Treiman. 2006. "Trends and racial differences in infant mortality in South Africa." Social Science E Medicine 62:1126-1137.

Coffey, Diane. 2015. "Prepregnancy body mass and weight gain during pregnancy in India and sub-Saharan Africa." Proceedings of the National Academy of Sciences p. 201416964.

Coffey, Diane, Ashwini Deshpande, Jeffrey Hammer, and Dean Spears. 2019. "Local social inequality, economic inequality, and disparities in child height in India." Demography 56:1427-1452.

Coffey, Diane, Payal Hathi, Nidhi Khurana, and Amit Thorat. 2018. "Explicit prejudice: Evidence from a new survey of social attitudes." Economic E Political Weekly 53:46-54. 
Datta, Saugato and Vikram Pathania. 2016. "For whom does the phone (not) ring? Discrimination in the rental housing market in Delhi, India." Technical report, WIDER Working Paper.

Deaton, Angus. 2003. "Health, inequality, and economic development." Journal of Economic Literature 41:113-158.

Demyttenaere, Koen, Ronny Bruffaerts, J Posada-Villa, I Gasquet, V Kovess, JPeal Lepine, MC Angermeyer, S d Bernert, G De Girolamo, P Morosini, et al. 2004. "Prevalence, severity, and unmet need for treatment of mental disorders in the World Health Organization World Mental Health Surveys." JAMA 291:2581-2590.

Desai, Sonalde and Veena Kulkarni. 2008. "Changing educational inequalities in India in the context of affirmative action." Demography 45:245-270.

Desai, Sonalde and Reeve Vanneman. 2015. "India human development survey-II (IHDSII), 2011-12. ICPSR36151-v2." Ann Arbor, MI: Inter-university Consortium for Political and Social Research [distributor] 31.

Deshpande, Ashwini. 2017. The grammar of caste: Economic discrimination in contemporary India. Oxford.

Deshpande, Ashwini and Dean Spears. 2016. "Who is the identifiable victim? Caste and charitable giving in modern India." Economic Development and Cultural Change 64:299321.

Diener, Ed, Eunkook M Suh, Richard E Lucas, and Heidi L Smith. 1999. "Subjective wellbeing: Three decades of progress." Psychological Bulletin 125:276.

DiNardo, John, Nicole Fortin, and Thomas Lemieux. 1996. "Labor market institutions and the distribution of wages, 1973-1992: A semiparametric approach." Econometrica 64:1001-1044.

Do, D Phuong, Reanne Frank, and Brian Karl Finch. 2012. "Does SES explain more of the black/white health gap than we thought? Revisiting our approach toward understanding racial disparities in health." Social Science \& Medicine 74:1385-1393.

Earl, Tara, David Williams, and Stacey Anglade. 2011. "An update on the mental health of Black Americans: Puzzling dilemmas and needed research." Journal of Black Psychology 37:485-498.

Elo, Irma T and Samuel H Preston. 1996. "Educational differentials in mortality: United States, 1979-1985." Social Science \& Medicine 42:47-57.

Fazal, Tanweer. 2020. The Minority Conundrum: Living in Majoritarian Times. Penguin Random House India Private Limited.

Filmer, Deon and Lant H Pritchett. 2001. "Estimating wealth effects without expenditure data - or tears: An application to educational enrollments in states of India." Demography 38:115-132. 
Geruso, Michael. 2012. "Black-white disparities in life expectancy: how much can the standard SES variables explain?" Demography 49:553-574.

Ghassem-Fachandi, Parvis. 2012. Pogrom in Gujarat: Hindu nationalism and anti-Muslim violence in India. Princeton University Press.

Goosby, Bridget J, Jacob E Cheadle, and Colter Mitchell. 2017. "Stress-Related Biosocial Mechanisms of Discrimination and African American Health Inequities." Annual Review of Sociology .

Gorman, Bridget K and Jen'nan Ghazal Read. 2006. "Gender Disparities in Adult Health: An Examination of Three Measures of Morbidity." Journal of health and social behavior 47:95-110.

Guillot, Michel and Keera Allendorf. 2010. "Hindu-Muslim differentials in child mortality in India." Genus 66.

Gupta, Aashish, Nazar Khalid, Payal Hathi, Nikhil Srivastav, Sangita Vyas, and Diane Coffey. 2019. "Coercion, Construction, and 'ODF paper pe': Swachh Bharat According to Local Officials." The India Forum .

Gururaj, G, M Varghese, V Benegal, GN Rao, K Pathak, LK Singh, RY Mehta, D Ram, TM Shibukumar, and A Kokane. 2016. "National Mental Health Survey of India, 201516: prevalence, patterns and outcomes." NIMHANS Publication pp. 90-121.

Hasan, Mushirul and Mohammad Asaduddin. 2000. Image and Representation: Stories of Muslim Lives in India. Oxford University Press, USA.

Hawes, Armani M, William G Axinn, and Dirgha J Ghimire. 2016. "Ethnicity and psychiatric disorders." Annals of psychiatry and mental health 4.

Housen, Tambri, Annick Lenglet, Cono Ariti, Showkat Shah, Helal Shah, Shabnum Ara, Kerri Viney, Simon Janes, and Giovanni Pintaldi. 2017. "Prevalence of anxiety, depression and post-traumatic stress disorder in the Kashmir Valley." BMJ global health 2:e000419.

Hughes, Michael and Melvin E Thomas. 1998. "The continuing significance of race revisited: A study of race, class, and quality of life in America, 1972 to 1996." American Sociological Review pp. 785-795.

Hummer, Robert. 1996. "Black-white differences in health and mortality: A review and conceptual model." The Sociological Quarterly 37:105-125.

Jackson, Pamela Braboy, David R Williams, Dan J Stein, Allen Herman, Stacey L Williams, and Deidre L Redmond. 2010. "Race and Psychological Distress The South African Stress and Health Study." Journal of health and social behavior 51:458-477.

Jacob, K Stanly and Vikram Patel. 2014. "Classification of mental disorders: a global mental health perspective." The Lancet 383:1433-1435. 
Jadhav, Sushrut and Surineder Jodhka. 2012. "Caste, culture, and the clinic." Seminar India 633.

Jadhav, Sushrut, David Mosse, and Ned Dostaler. 2016. "Minds of caste: Discrimination and its affects." Anthropology Today pp. 1-2.

Jeelani, Mehboob. 2012. “Unhealed Wounds:.” Caravan Magazine .

Jodhka, Surinder S. 2002. "Caste and untouchability in rural Punjab." Economic and Political Weekly pp. 1813-1823.

Kamdar, Mira. 2020. "What happened in Delhi was a pogrom." The Atlantic .

Kandukuri, Divya. 2018. “Caste and mental health." Roundtable India .

Kessler, Ronald and Evelyn Bromet. 2013. "The epidemiology of depression across cultures." Annual Review of Public Health 34:119-138.

Kessler, Ronald C and Harold W Neighbors. 1986. "A new perspective on the relationships among race, social class, and psychological distress." Journal of Health and Social Behavior pp. 107-115.

Link, Bruce G and Jo Phelan. 1995. "Social conditions as fundamental causes of disease." Journal of Health and Social Behavior pp. 80-94.

Marx, Karl, Francis Wheen, and James Ledbetter. 2007. Dispatches for the New York Tribune: Selected Journalism of Karl Marx. Penguin Classics.

Mathias, Kaaren, Isabel Goicolea, Michelle Kermode, Lawrence Singh, Rahul Shidhaye, and Miguel San Sebastian. 2015. "Cross-sectional study of depression and help-seeking in Uttarakhand, North India." BMJ open 5:e008992.

Mondal, Sudipto. 2016. "Rohith Vemula: An unfinished portrait." Hindustan Times .

Myer, Landon, Dan J Stein, Anna Grimsrud, Soraya Seedat, and David R Williams. 2008. "Social determinants of psychological distress in a nationally-representative sample of South African adults." Social science \& medicine 66:1828-1840.

Noh, Samuel, Morton Beiser, Violet Kaspar, Feng Hou, and Joanna Rummens. 1999. "Perceived racial discrimination, depression, and coping: A study of Southeast Asian refugees in Canada." Journal of Health and Social Behavior pp. 193-207.

Office of the Registrar General. 2011. "Census of India 2011: Household Listing Operations." Office of the Registrar and General Census Commissioner of India .

Pager, Devah, Bart Bonikowski, and Bruce Western. 2009. "Discrimination in a low-wage labor market: A field experiment." American Sociological Review 74:777-799.

Patel, Vikram, Ricardo Araya, Mauricio De Lima, Ana Ludermir, and Charles Todd. 1999. "Women, poverty and common mental disorders in four restructuring societies." Social science \& medicine 49:1461-1471. 
Pathak, Suryasikha. 2012. "Ethnic violence in Bodoland." Economic and Political Weekly pp. 19-23.

Pawar, Dagdu Maruti and Jerry Pinto. 2015. Baluta. Speaking Tiger.

Poongothai, Subramani, Rajendra Pradeepa, Anbhazhagan Ganesan, and Viswanathan Mohan. 2009. "Prevalence of depression in a large urban South Indian population: The Chennai Urban Rural Epidemiology study (CURES-70)." PloS one 4:e7185.

Preston, Samuel, Patrick Heuveline, and Michael Guillot. 2000. "Demography: measuring and modeling population processes. 2001." Malden, MA: Blackwell Publishers .

Prime Minister's High Level Committee. 2006. "Social, economic, and educational status of the Muslim community of India: A report." official report, Government of India.

Prost, Audrey, Rashmi Lakshminarayana, Nirmala Nair, Prasanta Tripathy, Andrew Copas, Rajendra Mahapatra, Shibanand Rath, Raj Kumar Gope, Suchitra Rath, Aparna Bajpai, et al. 2012. "Predictors of maternal psychological distress in rural India: a crosssectional community-based study." Journal of affective disorders 138:277-286.

Ram, Usha, Lisa Strohschein, and Kirti Gaur. 2014. “Gender Socialization: Differences between Male and Female Youth in India and Associations with Mental Health." International Journal of Population Research .

Ramaiah, Avatthi. 2015. "Health status of dalits in India." Economic and Political Weekly 50:70-74.

Ravi, Shamika and Monika Engler. 2015. "Workfare as an effective way to fight poverty: The case of India's NREGS." World Development 67:57-71.

Rodríguez, Germán. 2007. Lecture Notes on Generalized Linear Models. URL: http://data.princeton.edu/wws509/notes/.

Sagar, Rajesh, Rakhi Dandona, Gopalkrishna Gururaj, RS Dhaliwal, Aditya Singh, Alize Ferrari, Tarun Dua, Atreyi Ganguli, Mathew Varghese, Joy K Chakma, et al. 2020. "The burden of mental disorders across the states of India: the Global Burden of Disease Study 1990-2017." The Lancet Psychiatry 7:148-161.

Satheesh, Shone. 2019. "Payal Tadvi suicide case: The death of a doctor." LiveMint .

Shah, Ghanshyam, Harsh Mander, Sukhdeo Thorat, Satish Deshpande, and Amita Baviskar. 2006. "Untouchability in rural India." Untouchability in rural India. .

Spears, Dean. 2016. "Caste and Life Satisfaction in Rural North India." Economic E Political Weekly 51:13.

Spears, Dean and Michael Geruso. 2018. "Neighborhood sanitation and infant mortality." American Economic Journal: Applied Economics 10:125-162. 
Susewind, Raphael. 2013. Being Muslim and working for peace: Ambivalence and ambiguity in Gujarat. SAGE Publications India.

Tadvi, Abeda Salim and Radhika Vemula. 2019. "Writ petition under article 32 of the constitution seeking issuance of specific guidelines and/or directions in respect of caste based discrimination in higher educational institutions." Supreme Court of India .

Teltumbde, Anand. 2007. "Khairlanji and its aftermath: Exploding some myths." Economic and Political Weekly pp. 1019-1025.

Thorat, Amit and Omkar Joshi. 2015. "The continuing practice of untouchability in India: Patterns and mitigating influences." India Human Development Study Working Paper 3.

Thorat, Sukhadeo and Paul Attewell. 2007. "The legacy of social exclusion: A correspondence study of job discrimination in India." Economic and Political Weekly pp. 4141-4145.

Thorat, Sukhadeo and Katherine S Neuman. 2012. Blocked by caste: economic discrimination in modern India. Oxford University Press.

Thorat, Sukhadeo, KM Shyamprasad, and RK Srivastava. 2007. "Report of the committee to enquire into the allegation of differential treatment of SC/ST students in All India Institute of Medical Science, Delhi." Thorat committee pp. 2-77.

Vaid, Divya. 2014. "Caste in contemporary India: Flexibility and persistence." Annual Review of Sociology 40:391-410.

Valmiki, Omprakash and Arun Prabha Mukherjee. 2008. Joothan: An Untouchable's Life. Columbia University Press.

Vyas, Sangita, Aashish Gupta, and Payal Hathi. 2019. "Social disadvantage and life expectancy in nine Indian states." Technical report, ri.c.e.

Weber, Max. 2000. The religion of India: The sociology of Hinduism and Buddhism. The Free Press.

Weiner, Myron. 1983. “The political demography of Assam's anti-immigrant movement.” Population and Development Review pp. 279-292.

Whiteford, Harvey A, Louisa Degenhardt, Jürgen Rehm, Amanda J Baxter, Alize J Ferrari, Holly E Erskine, Fiona J Charlson, Rosana E Norman, Abraham D Flaxman, Nicole Johns, et al. 2013. "Global burden of disease attributable to mental and substance use disorders: findings from the Global Burden of Disease Study 2010." The Lancet 382:1575-1586.

Wilkinson, Steven I. 2006. Votes and violence: Electoral competition and ethnic riots in India. Cambridge University Press.

Williams, David R. 2012. "Miles to go before we sleep: Racial inequities in health." Journal of Health and Social Behavior 53:279-295. 
Williams, David R, Selina A Mohammed, Jacinta Leavell, and Chiquita Collins. 2010. "Race, socioeconomic status, and health: Complexities, ongoing challenges, and research opportunities." Annals of the New York Academy of Sciences 1186:69-101.

Williams, David R, Yan Yu, James S Jackson, and Norman B Anderson. 1997. “Racial differences in physical and mental health: Socio-economic status, stress and discrimination." Journal of Health Psychology 2:335-351.

Wood, Charles H and Peggy A Lovell. 1992. "Racial inequality and child mortality in Brazil." Social Forces 70:703-724.

World Health Organization. 2013. Study on Global AGEing and Adult Health. WHO \& IIPS.

Xaxa, Virginius. 2008. State, society, and tribes: Issues in post-colonial India. Pearson Education India.

Zheng, Hui and Patricia A Thomas. 2013. "Marital status, self-rated health, and mortality: overestimation of health or diminishing protection of marriage?" Journal of Health and Social Behavior 54:128-143. 


\section{Table 1: Summary statistics for the sample, overall and by social group}

\begin{tabular}{|c|c|c|c|c|c|c|c|c|}
\hline & \multicolumn{2}{|c|}{$\begin{array}{c}\text { Higher Caste } \\
\text { Hindu }\end{array}$} & \multicolumn{2}{|c|}{ Scheduled Caste } & \multicolumn{2}{|c|}{ Muslim } & \multicolumn{2}{|c|}{ Total } \\
\hline & mean & s.e. & mean & s.e. & mean & s.e. & mean & s.e. \\
\hline \multicolumn{9}{|c|}{ self-reported mental health outcomes (mild, moderate, severe, or extreme) } \\
\hline have depression & 0.41 & $(0.013)$ & $0.46 *$ & $(0.023)$ & $0.51 * *$ & $(0.032)$ & 0.43 & $(0.011)$ \\
\hline have anxiety & 0.49 & (0.014) & $0.57^{* *}$ & $(0.026)$ & $0.60 * *$ & $(0.031)$ & 0.52 & $(0.012)$ \\
\hline \multicolumn{9}{|l|}{ predictor variables } \\
\hline mean age & 41.7 & $(0.357)$ & $39.8^{* *}$ & $(0.472)$ & 41.0 & $(0.940)$ & 41.2 & $(0.304)$ \\
\hline female & 0.49 & $(0.010)$ & 0.47 & $(0.020)$ & 0.47 & (0.215) & 0.49 & $(0.007)$ \\
\hline mean \# of assets (out of 16) & 7.8 & (0.139) & $6.0^{* * *}$ & $(0.175)$ & $6.2^{* * *}$ & $(0.224)$ & 7.2 & $(0.117)$ \\
\hline \multicolumn{9}{|l|}{ asset wealth categories } \\
\hline $0-4$ assets & 0.16 & -- & 0.32 & -- & 0.28 & -- & 0.21 & -- \\
\hline 5 or 6 assets & 0.22 & -- & 0.29 & -- & 0.29 & -- & 0.24 & -- \\
\hline 7 or 8 assets & 0.21 & -- & 0.19 & -- & 0.24 & -- & 0.21 & -- \\
\hline 9 or 10 assets & 0.18 & -- & 0.13 & -- & 0.10 & -- & 0.16 & -- \\
\hline more than 10 assets & 0.23 & -- & 0.07 & -- & 0.08 & -- & 0.18 & -- \\
\hline mean years of education & 6.6 & $(0.205)$ & $4.5^{* * *}$ & $(0.304)$ & $4.0^{* * *}$ & $(0.403)$ & 5.7 & $(0.176)$ \\
\hline \multicolumn{9}{|l|}{ years of education categories } \\
\hline no education & 0.29 & -- & 0.45 & -- & 0.47 & -- & 0.35 & -- \\
\hline 1 to 5 & 0.16 & -- & 0.17 & -- & 0.20 & -- & 0.17 & -- \\
\hline 6 to 8 & 0.14 & -- & 0.14 & -- & 0.14 & -- & 0.14 & -- \\
\hline 9 to 12 & 0.26 & -- & 0.15 & -- & 0.13 & -- & 0.22 & -- \\
\hline more than 12 & 0.15 & -- & 0.08 & -- & 0.05 & -- & 0.12 & -- \\
\hline rural resident & 0.64 & $(0.028)$ & $0.81^{* * *}$ & $(0.034)$ & 0.65 & $(0.060)$ & 0.68 & $(0.027)$ \\
\hline log per-capita expenditure & 6.3 & $(0.032)$ & $6.1 * * *$ & $(0.037)$ & $6.0^{* * *}$ & $(0.049)$ & 6.2 & $(0.030)$ \\
\hline$n$ & 6,8 & 32 & $1,9 !$ & & 1,34 & & & 125 \\
\hline
\end{tabular}

Source: WHO SAGE, 2007-08. Means calculated using survey weights, and standard errors are clustered at the level of the primary sampling unit. Tests of significance from adjusted wald tests comparing Scheduled Castes and Muslims to Higher Caste Hindus are also shown $\left(+\mathrm{p}<.1,{ }^{*} \mathrm{p}<.05,{ }^{* *} \mathrm{p}<.01,{ }^{* * *} \mathrm{p}<.001\right)$. These tests were not conducted for asset categories and education categories. People who reported having mild, moderate, severe or extreme problems with depression or anxiety in the last 30 days were coded as having depression or anxiety. 
Table 2: Ordered logit regression showing odds-ratios for self-reported mental health outcomes by social group

panel a: depression

\begin{tabular}{|c|c|c|c|c|c|}
\hline & \multicolumn{5}{|c|}{$\begin{array}{l}\text { problems with feeling sad, low, or depressed } \\
\text { from } 1 \text { "none" to } 5 \text { "extreme" }\end{array}$} \\
\hline & $(1)$ & $(2)$ & (3) & (4) & (5) \\
\hline \multirow[t]{2}{*}{ Muslim } & $1.683^{* * *}$ & $1.513^{* * *}$ & $1.422 * *$ & $1.397 * *$ & $1.341^{*}$ \\
\hline & $(0.211)$ & $(0.185)$ & $(0.169)$ & $(0.168)$ & $(0.166)$ \\
\hline \multirow[t]{2}{*}{ Scheduled Caste } & $1.380 * *$ & $1.257^{*}$ & 1.149 & 1.139 & 1.035 \\
\hline & $(0.135)$ & $(0.123)$ & $(0.116)$ & $(0.115)$ & $(0.106)$ \\
\hline \multirow[t]{2}{*}{ Female } & $1.847^{* * *}$ & $1.611^{* * *}$ & $1.783^{* * *}$ & $1.816^{* * *}$ & $1.816 * * *$ \\
\hline & $(0.164)$ & $(0.155)$ & $(0.178)$ & $(0.182)$ & $(0.184)$ \\
\hline dummies for age (in years) & $x$ & $x$ & $x$ & $x$ & $x$ \\
\hline education categories & & $\mathrm{X}$ & $x$ & $x$ & $x$ \\
\hline asset categories & & & $\mathrm{X}$ & $\mathrm{X}$ & $x$ \\
\hline per capita log expenditure & & & & $x$ & $x$ \\
\hline rural residence & & & & & $x$ \\
\hline state dummies & & & & & $x$ \\
\hline$n$ & 10,125 & 10,125 & 10,125 & 10,125 & 10,125 \\
\hline \multicolumn{6}{|l|}{ panel b:anxiety } \\
\hline & \multicolumn{5}{|c|}{ problems with worry or anxiety } \\
\hline & \multicolumn{5}{|c|}{ from 1 "none" to 5 "extreme" } \\
\hline & (1) & $(2)$ & (3) & (4) & (5) \\
\hline Muslim & $1.870 * * *$ & $1.653 * * *$ & $1.557^{* * *}$ & $1.542 * *$ & $1.448 * *$ \\
\hline & $(0.257)$ & $(0.224)$ & $(0.207)$ & $(0.207)$ & $(0.196)$ \\
\hline \multirow[t]{2}{*}{ Scheduled Caste } & $1.485^{* * *}$ & $1.346 * *$ & $1.239 *$ & $1.233^{*}$ & 1.116 \\
\hline & $(0.157)$ & $(0.139)$ & $(0.130)$ & $(0.129)$ & $(0.111)$ \\
\hline \multirow[t]{2}{*}{ Female } & $2.030 * * *$ & $1.751 * * *$ & $1.920 * * *$ & $1.939 * * *$ & $2.024 * * *$ \\
\hline & $(0.197)$ & $(0.184)$ & $(0.203)$ & $(0.206)$ & $(0.213)$ \\
\hline dummies for age (in years) & $\mathrm{X}$ & $x$ & $x$ & $\mathrm{X}$ & $x$ \\
\hline education categories & & $x$ & $x$ & $x$ & $x$ \\
\hline asset categories & & & $x$ & $x$ & $x$ \\
\hline per capita log expenditure & & & & $x$ & $x$ \\
\hline rural residence & & & & & $x$ \\
\hline state dummies & & & & & $x$ \\
\hline$n$ & 10,125 & 10,125 & 10,125 & 10,125 & 10,125 \\
\hline
\end{tabular}

WHO SAGE, 2007-08. Exponentiated coefficients. Standard errors clustered at the level of the primary sampling unit in parentheses. $+\mathrm{p}<.1,{ }^{*} \mathrm{p}<.05,{ }^{* *} \mathrm{p}<.01,{ }^{* * *} \mathrm{p}<.001$. All regressions are weighed using national individual weights. 
Figure 1: Distributions of self-reported depression among Scheduled Castes, Muslims, and higher caste Hindus

panel a. Scheduled Castes \& higher caste Hindus

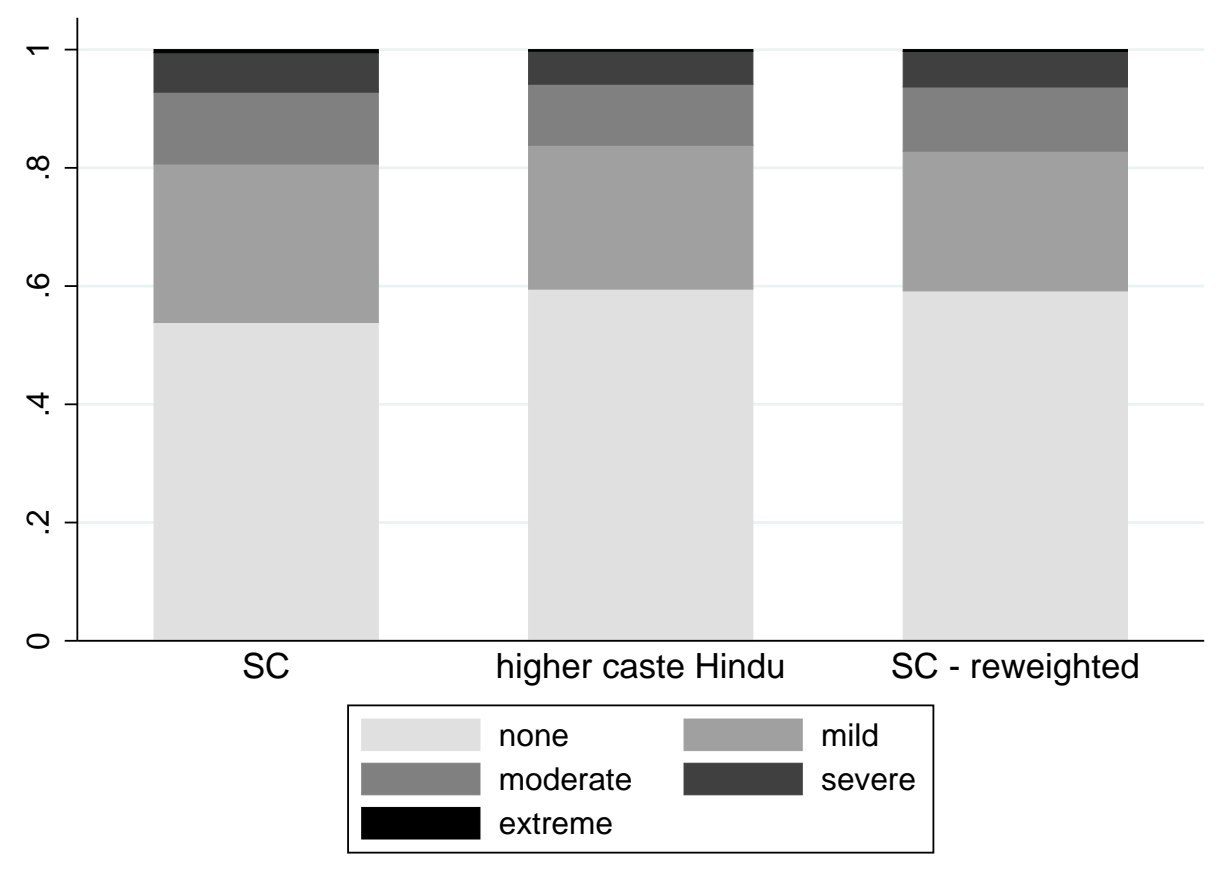

panel b. Muslims \& higher caste Hindus

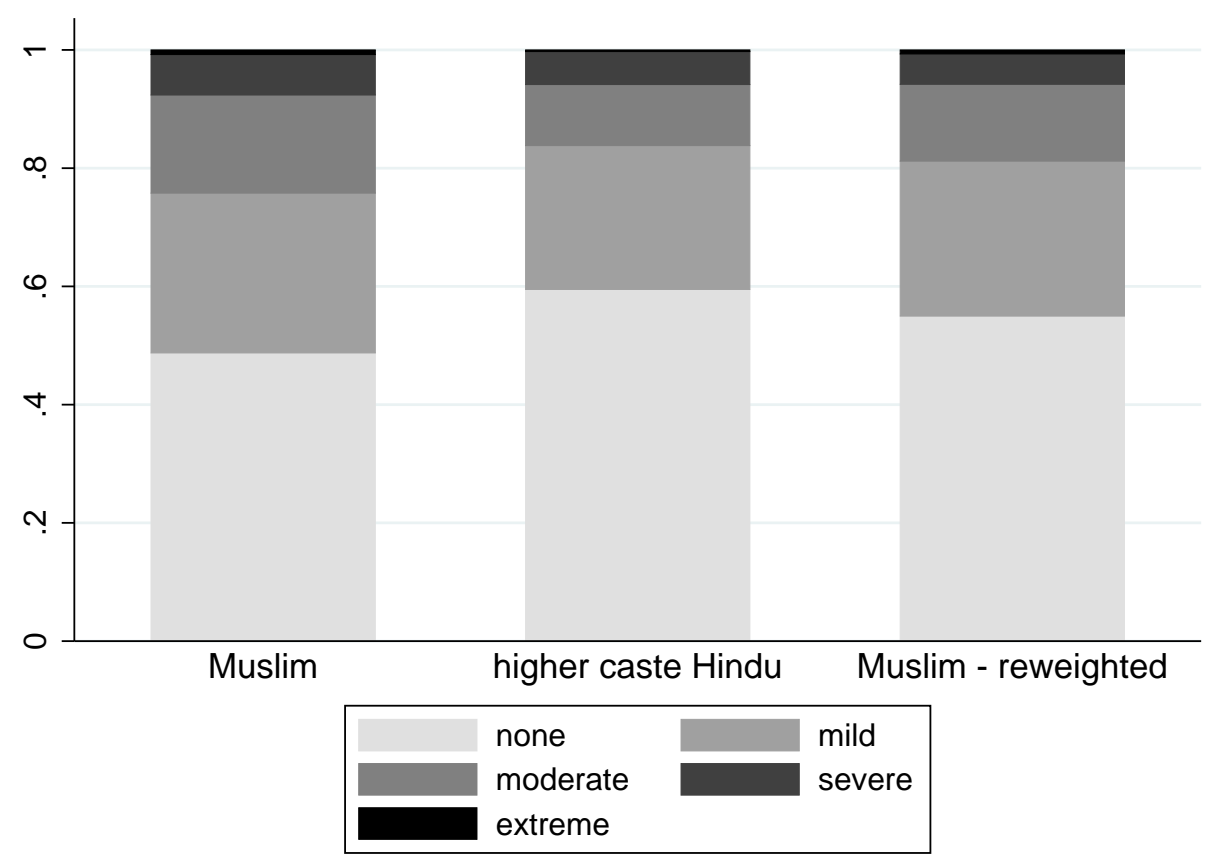

WHO SAGE, 2007-8. The leftmost distributions are self-reported distributions of depression among disadvantaged groups, and among higher caste Hindus, computed using sampling weights. The rightmost distributions are the reweighted distributions of depression among disadvantaged groups, where twentyfive education by asset categories are used in the reweighting function, as described in Section 3.2. 
Figure 2: Distributions of self-reported anxiety among Scheduled Castes, Muslims, and higher caste Hindus

panel a. Scheduled Castes \& higher caste Hindus

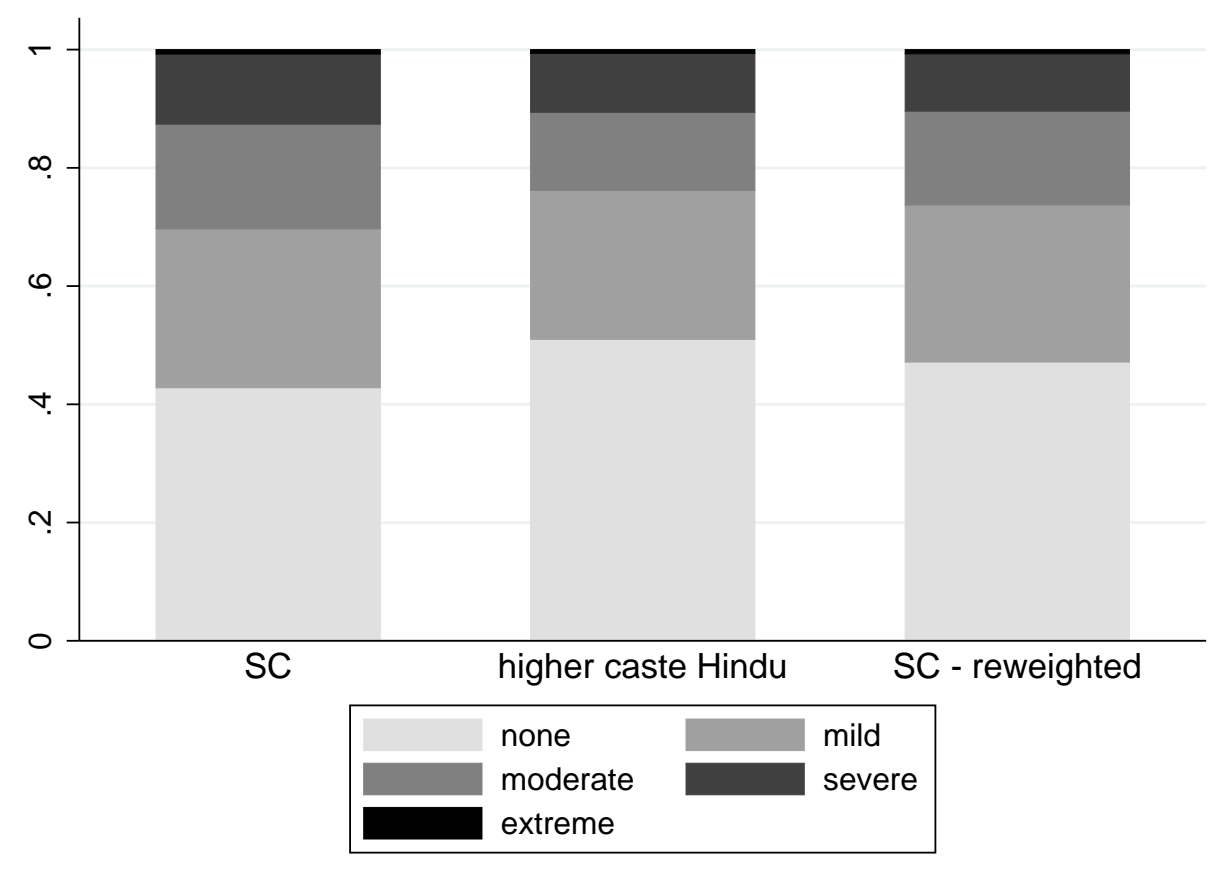

panel b. Muslims \& higher caste Hindus

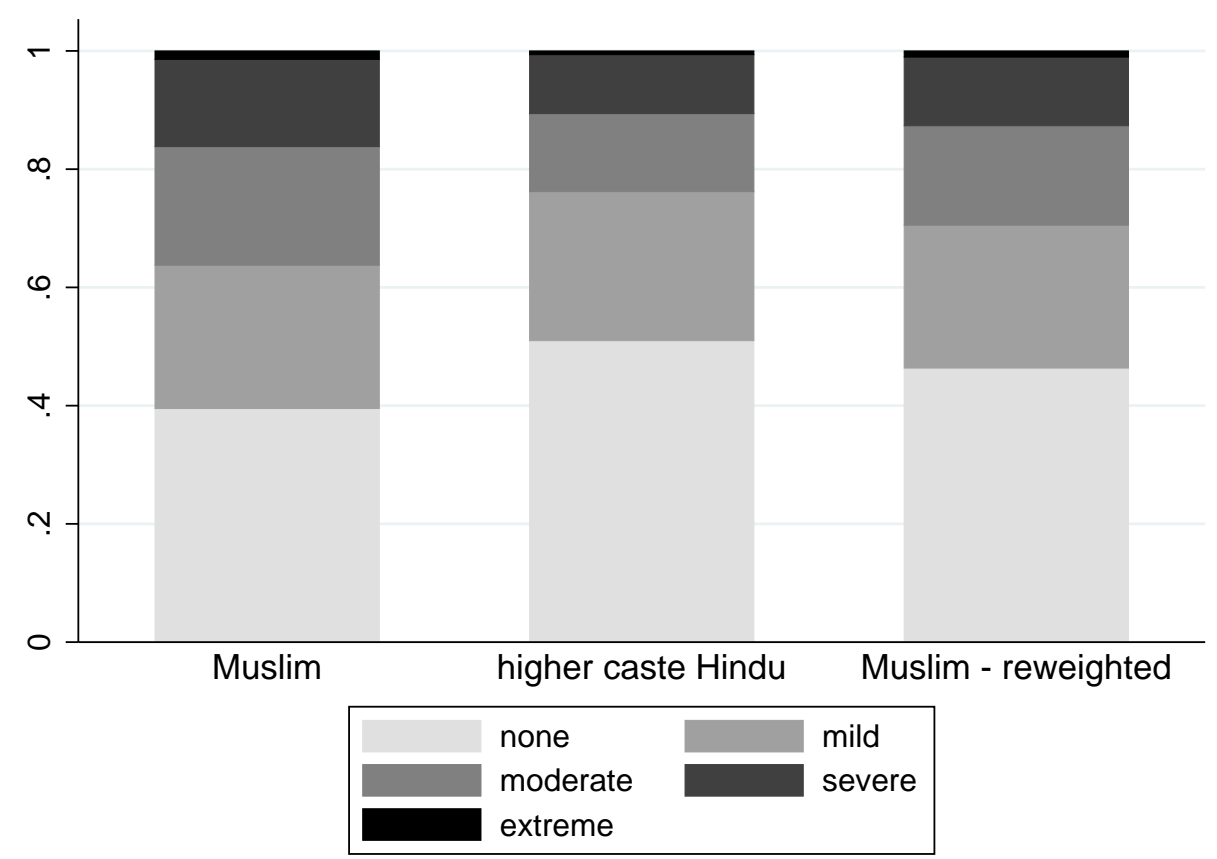

WHO SAGE, 2007-8. The leftmost distributions are self-reported distributions of anxiety among disadvantaged groups, and among higher caste Hindus, computed using sampling weights. The rightmost distributions are the reweighted distributions of anxiety among disadvantaged groups, where twenty-five education by asset categories are used in the reweighting function, as described in Section 3.2. 


\section{SUPPLEMENTARY APPENDIX}

\section{Appendix Tables}

Table A1 and A2 show results of regressions similar to those in Table 2 in the main text, except that they add interactions with assets and years of education. In general, the interactions show that association of higher asset wealth or years of education with mental health is not significantly different for Muslims or Scheduled Caste respondents than it is for higher caste Hindu respondents.

Table A3 presents odds-ratios from logistic regressions for dichotomized self-reported depression and anxiety. The two outcomes have been dichotomized such that reporting mild, moderate, severe or extreme problems implies having depression and anxiety. Only two models are shown for each of the outcome - a basic model with age and sex controls, and a full model with additional controls for state, rural residence, assets, education, and expenditure. The results of the logistic model are very similar to that of the ordered logit model in Table 2.

Table A4 shows odds-ratios from ordered logit or logistic regressions for alternative selfreported mental health outcomes available from the WHO-SAGE. For most mental health outcomes, Scheduled Castes and Muslims are significantly more likely to report having problems with mental health than higher-caste Hindus.

Table A5 shows that controlling for socioeconomic status by controlling for five asset categories or 17 individual binary assets does not change the results.

Tables A6 and A7 show logistic regressions stratified with state, with the basic and the full models, for anxiety and depression. It is important to remember that the state-wise samples are much smaller than the combined sample, and may not be powered to detect social group differences. Still, the results reveal that Muslims and Scheduled Castes are more likely to report having depression or anxiety across states.

Table A8 presents summary statistics for WHO-SAGE respondents, aged 18 to 85 , and compares them to a nationally representative sample of adults of the same ages from the India Human Development Survey, 2011. Summary statistics are presented separately for Dalits, Muslims, and upper caste Hindus. The table shows that WHO SAGE oversampled 
older adults. Th SAGE respondents are, on average, poorer and less educated than the average Indian adult in each social group. This is likely because the SAGE was focused on health of older adults, and was conducted earlier than the IHDS-II. Patterns of disadvantage are similar in the WHO-SAGE and the IHDS. In both the surveys, Scheduled Castes are the most disadvantaged. Muslims are less likely to own assets have less education than higher caste Hindus. The only difference is in the proportion of Muslims which live in an urban area - in the WHO-SAGE, Muslims are less likely to be urban residents compared to higher caste Hindus, but nationally, they are more urbanized than higher-caste Hindus.

\section{Appendix Figures}

Figure A1 shows differences in self-reported mental health among the three social groups by measures of socioeconomic status. Largely, the figures do not reveal a consistent pattern to understand differences by social group and socioeconomic status. Although there are levels of education and assets without differences in mental health between the social groups, differences do exist for most levels. Moreover, disparities can be seen at both high and both ends of the distribution of socioeconomic status, as well as in the middle.

Figure A2 shows age patterns for dichotomous mental health outcomes for the three social groups. Age-misreporting and heaping is an important concern for data collection efforts in developing countries, and age-misreporting is likely to be higher among Scheduled Castes and Muslims, given that they are poorer and less-educated. Another concern is selection and mortality, especially above sixty. Still, these graphs show a pattern well-known to mental health researchers, that with age, mental health tends to worsen. Overall, Muslims and Scheduled Caste Hindus have worse mental health outcomes when compared to higher Caste Hindus at most ages.

Figure A3 shows differences in self-reported mental health by sex and 95\% Confidence Intervals. These confidence intervals are constructed accounting for the clustering of observations in the primary sampling unit. The figure shows that disparities in mental health can be seen for both men and women. 
Table A1: Ordered logit regressions do not find evidence that social group interacts with asset wealth to predict self-reported mental health

\begin{tabular}{|c|c|c|}
\hline & depression & anxiety \\
\hline Muslim & $\begin{array}{l}1.424+ \\
(0.304)\end{array}$ & $\begin{array}{l}1.642 * \\
(0.379)\end{array}$ \\
\hline Scheduled Caste & $\begin{array}{c}0.914 \\
(0.135)\end{array}$ & $\begin{array}{c}1.093 \\
(0.183)\end{array}$ \\
\hline Female & $\begin{array}{c}1.870 * * * \\
(0.172)\end{array}$ & $\begin{array}{c}2.052 * * * \\
(0.203)\end{array}$ \\
\hline 0 - 4 assets (reference) & & \\
\hline 5 or 6 assets & $\begin{array}{l}0.635 * * \\
(0.0883)\end{array}$ & $\begin{array}{c}0.818 \\
(0.122)\end{array}$ \\
\hline 7 or 8 assets & $\begin{array}{l}0.672 * * \\
(0.0970)\end{array}$ & $\begin{array}{l}0.656 * * \\
(0.0901)\end{array}$ \\
\hline 9 or 10 assets & $\begin{array}{c}0.484 * * * \\
(0.0756)\end{array}$ & $\begin{array}{c}0.447 * * * \\
(0.0675)\end{array}$ \\
\hline more than 10 assets & $\begin{array}{c}0.361^{* * *} \\
(0.0528)\end{array}$ & $\begin{array}{c}0.423 * * * \\
(0.0610)\end{array}$ \\
\hline 5 or 6 assets $X$ Muslim & $\begin{array}{c}1.411 \\
(0.395)\end{array}$ & $\begin{array}{c}1.241 \\
(0.390)\end{array}$ \\
\hline 7 or 8 assets $X$ Muslim & $\begin{array}{c}0.915 \\
(0.301)\end{array}$ & $\begin{array}{c}0.725 \\
(0.262)\end{array}$ \\
\hline 9 or 10 assets $X$ Muslim & $\begin{array}{c}0.502 \\
(0.219)\end{array}$ & $\begin{array}{c}1.108 \\
(0.361)\end{array}$ \\
\hline more than 10 assets $X$ Muslim & $\begin{array}{c}0.930 \\
(0.285)\end{array}$ & $\begin{array}{c}0.764 \\
(0.269)\end{array}$ \\
\hline 5 or 6 assets $X$ Scheduled Caste & $\begin{array}{c}1.801 * * \\
(0.385)\end{array}$ & $\begin{array}{c}1.349 \\
(0.301)\end{array}$ \\
\hline 7 or 8 assets $X$ Scheduled Caste & $\begin{array}{c}1.263 \\
(0.306)\end{array}$ & $\begin{array}{c}1.300 \\
(0.335)\end{array}$ \\
\hline 9 or 10 assets X Scheduled Caste & $\begin{array}{c}1.147 \\
(0.310)\end{array}$ & $\begin{array}{c}0.930 \\
(0.252)\end{array}$ \\
\hline more than 10 assets $X$ Scheduled Caste & $\begin{array}{c}1.151 \\
(0.567)\end{array}$ & $\begin{array}{c}1.193 \\
(0.573)\end{array}$ \\
\hline$n$ & 10,125 & 10,125 \\
\hline
\end{tabular}

WHO SAGE, 2007-08. Exponentiated coefficients. Standard errors clustered at the level of the primary sampling unit in parentheses. $+\mathrm{p}<.1,{ }^{*} \mathrm{p}<.05,{ }^{* *} \mathrm{p}<.01,{ }^{* * *} \mathrm{p}<.001$. All regressions are weighed using national individual weights. 


\section{Table A2: Ordered logit regressions do not find evidence that social group interacts with education to predict self-reported mental health}

\begin{tabular}{|c|c|c|}
\hline & depression & anxiety \\
\hline Muslim & $\begin{array}{l}1.507^{*} \\
(0.240)\end{array}$ & $\begin{array}{c}3.809 * * * \\
(1.339)\end{array}$ \\
\hline Scheduled Caste & $\begin{array}{c}1.186 \\
(0.173)\end{array}$ & $\begin{array}{l}1.676+ \\
(0.458)\end{array}$ \\
\hline Female & $\begin{array}{c}1.759 * * * \\
(0.185)\end{array}$ & $\begin{array}{c}0.932 \\
(0.0914)\end{array}$ \\
\hline no education (reference) & & \\
\hline 1 - 5 years of education & $\begin{array}{c}0.881 \\
(0.118)\end{array}$ & $\begin{array}{c}0.840 \\
(0.119)\end{array}$ \\
\hline 6 - 8 years of education & $\begin{array}{l}0.773+ \\
(0.104)\end{array}$ & $\begin{array}{l}0.748+ \\
(0.113)\end{array}$ \\
\hline $9-12$ years of education & $\begin{array}{c}0.722 * \\
(0.0983)\end{array}$ & $\begin{array}{c}0.621^{* * *} \\
(0.0811)\end{array}$ \\
\hline more than 12 years of education & $\begin{array}{c}0.448 * * * \\
(0.0875)\end{array}$ & $\begin{array}{c}0.426 * * * \\
(0.0780)\end{array}$ \\
\hline 1 - 5 years of education X Muslim & $\begin{array}{c}1.384 \\
(0.359)\end{array}$ & $\begin{array}{c}1.557 \\
(0.422)\end{array}$ \\
\hline 6 - 8 years of education $X$ Muslim & $\begin{array}{c}1.537 \\
(0.530)\end{array}$ & $\begin{array}{c}0.967 \\
(0.385)\end{array}$ \\
\hline 9 - 12 years of education X Muslim & $\begin{array}{c}1.017 \\
(0.368)\end{array}$ & $\begin{array}{c}1.025 \\
(0.293)\end{array}$ \\
\hline more than 12 years of education X Muslim & $\begin{array}{c}0.894 \\
(0.366)\end{array}$ & $\begin{array}{c}0.905 \\
(0.438)\end{array}$ \\
\hline 1 - 5 years of education X Scheduled Caste & $\begin{array}{c}0.928 \\
(0.214)\end{array}$ & $\begin{array}{c}1.430 \\
(0.325)\end{array}$ \\
\hline 6 - 8 years of education $X$ Scheduled Caste & $\begin{array}{c}0.826 \\
(0.227)\end{array}$ & $\begin{array}{c}0.973 \\
(0.282)\end{array}$ \\
\hline 9 - 12 years of education $X$ Scheduled Caste & $\begin{array}{c}1.042 \\
(0.278)\end{array}$ & $\begin{array}{l}1.530+ \\
(0.390)\end{array}$ \\
\hline more than 12 years $X$ Scheduled Caste & $\begin{array}{c}0.596 \\
(0.292)\end{array}$ & $\begin{array}{c}0.921 \\
(0.441)\end{array}$ \\
\hline$n$ & 10,125 & 10,125 \\
\hline
\end{tabular}

WHO SAGE, 2007-08. Exponentiated coefficients. Standard errors clustered at the level of the primary sampling unit in parentheses. $+\mathrm{p}<.1,{ }^{*} \mathrm{p}<.05,{ }^{* *} \mathrm{p}<.01,{ }^{* * *} \mathrm{p}<.001$. All regressions are weighed using national individual weights. 
Table A3: Odds-ratios from logistic regressions for having any selfreported depression or anxiety (mild, moderate, severe, or extreme)

\begin{tabular}{lccccc}
\hline & \multicolumn{3}{c}{ depression } & & \multicolumn{2}{c}{ anxiety } \\
\cline { 2 - 3 } \cline { 5 - 6 } & $(1)$ & $(2)$ & & $(3)$ & $(4)$ \\
\hline muslim & $1.664^{* * *}$ & $1.327^{*}$ & & $1.787^{* * *}$ & $1.409^{*}$ \\
& $(0.230)$ & $(0.187)$ & & $(0.253)$ & $(0.193)$ \\
scheduled caste & & & & & \\
& $1.398^{* *}$ & 1.057 & & $1.543^{* * *}$ & 1.148 \\
& $(0.149)$ & $(0.116)$ & & $(0.184)$ & $(0.136)$ \\
female & & & & & \\
& $1.799^{* * *}$ & $1.758^{* * *}$ & & $2.011^{* * *}$ & $2.041^{* * *}$ \\
& $(0.175)$ & $(0.198)$ & & $(0.207)$ & $(0.233)$ \\
female & & & & \\
age dummies & $\mathrm{X}$ & $\mathrm{X}$ & & $\mathrm{X}$ & $\mathrm{X}$ \\
state dummies & $\mathrm{X}$ & $\mathrm{X}$ & & $\mathrm{X}$ & $\mathrm{X}$ \\
rural residence & & $\mathrm{X}$ & & $\mathrm{X}$ \\
asset categories & & $\mathrm{X}$ & & $\mathrm{X}$ \\
educational categories & & $\mathrm{X}$ & & $\mathrm{X}$ \\
per capita log expenditure & & $\mathrm{X}$ & & $\mathrm{X}$ \\
& & $\mathrm{X}$ & & $\mathrm{X}$ \\
$n$ & 10125 & 10125 & & 10125 & 10125 \\
\hline
\end{tabular}

WHO SAGE, 2007-08. Exponentiated coefficients. Standard errors clustered at the level of the primary sampling unit in parentheses. $+\mathrm{p}<.1,{ }^{*} \mathrm{p}<.05,{ }^{* *} \mathrm{p}<.01,{ }^{* * *} \mathrm{p}<.001$. All regressions are weighed using national individual weights. 


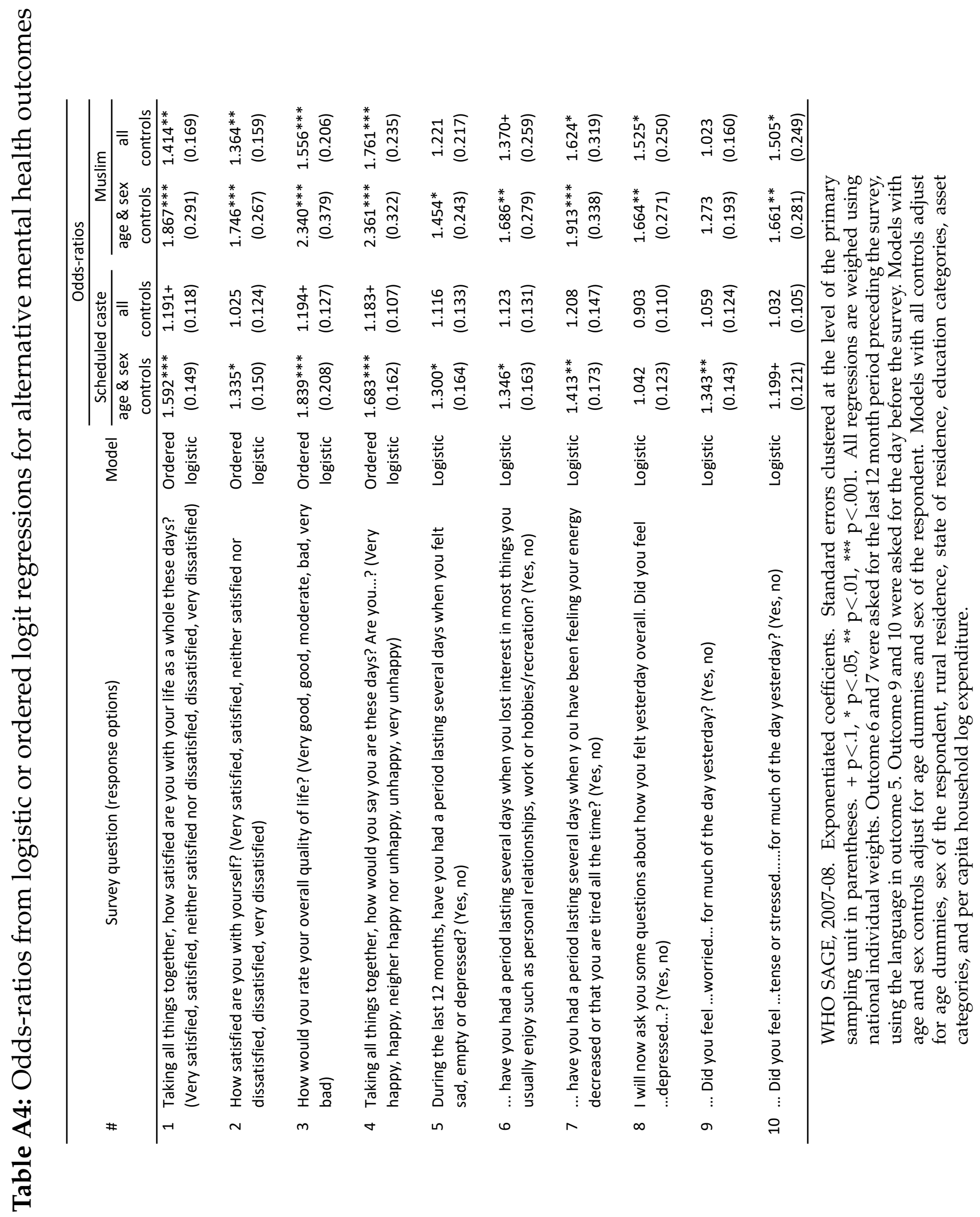


Table A5: Odds-ratios from ordered logit regressions for reporting depression and anxiety, with controls for asset categories and assets controlled individually

\begin{tabular}{lccccc}
\hline & \multicolumn{2}{c}{ depression } & & \multicolumn{2}{c}{ anxiety } \\
\cline { 2 - 3 } \cline { 5 - 6 } & $(1)$ & $(2)$ & & $(3)$ & $(4)$ \\
\hline muslim & $1.402^{* *}$ & $1.399^{* *}$ & & $1.499^{* *}$ & $1.528^{* *}$ \\
& $(0.172)$ & $(0.174)$ & & $(0.197)$ & $(0.199)$ \\
scheduled caste & 1.056 & 1.052 & & 1.128 & 1.113 \\
& $(0.108)$ & $(0.107)$ & & $(0.115)$ & $(0.112)$ \\
& & & & & \\
asset categories & $\mathrm{X}$ & & & $\mathrm{X}$ & \\
all 17 assets & & $\mathrm{X}$ & & $\mathrm{X}$ & $\mathrm{X}$ \\
sex & $\mathrm{X}$ & $\mathrm{X}$ & & $\mathrm{X}$ & $\mathrm{X}$ \\
age dummies & $\mathrm{X}$ & $\mathrm{X}$ & & $\mathrm{X}$ & $\mathrm{X}$ \\
rural & $\mathrm{X}$ & $\mathrm{X}$ & & $\mathrm{X}$ & $\mathrm{X}$ \\
state dummies & $\mathrm{X}$ & $\mathrm{X}$ & & $\mathrm{X}$ & $\mathrm{X}$ \\
& & & & & \\
$\mathrm{N}$ & 10125 & 10125 & & 10125 & 10125 \\
\hline
\end{tabular}

WHO SAGE, 2007-08. Exponentiated coefficients. Standard errors clustered at the level of the primary sampling unit in parentheses. $+\mathrm{p}<.1,{ }^{*} \mathrm{p}<.05,{ }^{* *} \mathrm{p}<.01,{ }^{* * *} \mathrm{p}<.001$. All regressions are weighed using national individual weights. 
Table A6: Odds-ratios from logistic regressions for having any selfreported anxiety (mild, moderate, severe, or extreme) by state

\begin{tabular}{|c|c|c|c|c|c|c|}
\hline & \multicolumn{2}{|c|}{ Assam } & \multicolumn{2}{|c|}{ Karnataka } & \multicolumn{2}{|c|}{ Maharashtra } \\
\hline & $(1)$ & $(2)$ & $(3)$ & (4) & $(5)$ & (6) \\
\hline \multirow[t]{2}{*}{ muslim } & $4.536 * * *$ & $3.401^{* * *}$ & 1.470 & 1.812 & 1.379 & 1.235 \\
\hline & $(1.282)$ & $(1.103)$ & $(0.392)$ & $(0.664)$ & $(0.570)$ & $(0.466)$ \\
\hline \multirow[t]{2}{*}{ scheduled caste } & $1.709+$ & 1.397 & 1.548 & 0.851 & $1.746^{*}$ & 1.484 \\
\hline & $(0.472)$ & $(0.444)$ & $(0.466)$ & $(0.232)$ & $(0.437)$ & $(0.415)$ \\
\hline female & $\mathrm{x}$ & $\mathrm{x}$ & $\mathrm{x}$ & $\mathrm{x}$ & $x$ & $x$ \\
\hline age dummies & $x$ & $x$ & $x$ & $x$ & $x$ & $x$ \\
\hline rural residence & & $x$ & & $x$ & & $x$ \\
\hline asset categories & & $x$ & & $\mathrm{x}$ & & $x$ \\
\hline educational categories & & $x$ & & $x$ & & $x$ \\
\hline per capita log expenditure & & $x$ & & $x$ & & $x$ \\
\hline$n$ & 931 & 931 & 1400 & 1400 & 1804 & 1804 \\
\hline
\end{tabular}

\begin{tabular}{|c|c|c|c|c|c|c|}
\hline & \multicolumn{2}{|c|}{ Rajasthan } & \multicolumn{2}{|c|}{ Uttar Pradesh } & \multicolumn{2}{|c|}{ West Bengal } \\
\hline & (7) & (8) & (9) & (10) & (11) & (12) \\
\hline \multirow[t]{2}{*}{ muslim } & 1.711 & 1.581 & 1.217 & 1.084 & $2.937 * *$ & 1.579 \\
\hline & $(0.618)$ & $(0.596)$ & $(0.273)$ & $(0.264)$ & (1.139) & $(0.513)$ \\
\hline \multirow[t]{2}{*}{ scheduled caste } & 1.320 & 1.236 & $1.578^{*}$ & 1.372 & 1.224 & 0.659 \\
\hline & $(0.272)$ & $(0.256)$ & $(0.338)$ & $(0.295)$ & $(0.355)$ & (0.193) \\
\hline female & $\mathrm{x}$ & $\mathrm{x}$ & $\mathrm{x}$ & $\mathrm{x}$ & $\mathrm{x}$ & $\mathrm{x}$ \\
\hline age dummies & $x$ & $x$ & $x$ & $x$ & $x$ & $x$ \\
\hline rural residence & & $x$ & & $x$ & & $x$ \\
\hline asset categories & & $x$ & & $x$ & & $x$ \\
\hline educational categories & & $\mathrm{x}$ & & $\mathrm{x}$ & & $\mathrm{x}$ \\
\hline per capita log expenditure & & $x$ & & $x$ & & $x$ \\
\hline$n$ & 1937 & 1937 & 2117 & 2117 & 1849 & 1849 \\
\hline
\end{tabular}

WHO SAGE, 2007-08. Exponentiated coefficients. Standard errors clustered at the level of the primary sampling unit in parentheses. $+\mathrm{p}<.1,{ }^{*} \mathrm{p}<.05,{ }^{* *} \mathrm{p}<.01,{ }^{* * *} \mathrm{p}<.001$. All regressions are weighed using national individual weights. 
Table A7: Odds-ratios from logistic regressions for having any depression (mild, moderate, severe, or extreme) by state

\begin{tabular}{|c|c|c|c|c|c|c|}
\hline & \multicolumn{2}{|c|}{ Assam } & \multicolumn{2}{|c|}{ Karnataka } & \multicolumn{2}{|c|}{ Maharashtra } \\
\hline & $(1)$ & $(2)$ & (3) & (4) & $(5)$ & (6) \\
\hline \multirow[t]{2}{*}{ muslim } & $3.917^{* * *}$ & $3.464^{* * *}$ & 1.091 & 1.391 & $2.871+$ & $2.522+$ \\
\hline & $(1.039)$ & $(0.954)$ & $(0.353)$ & $(0.545)$ & $(1.686)$ & $(1.377)$ \\
\hline \multirow[t]{2}{*}{ scheduled caste } & 1.535 & 1.433 & 1.534 & 0.849 & 1.378 & 1.094 \\
\hline & (0.399) & $(0.395)$ & $(0.422)$ & $(0.227)$ & $(0.347)$ & $(0.285)$ \\
\hline female & $\mathrm{x}$ & $\mathrm{x}$ & $\mathrm{x}$ & $\mathrm{x}$ & $x$ & $x$ \\
\hline age dummies & $x$ & $x$ & $x$ & $x$ & $x$ & $x$ \\
\hline rural residence & & $x$ & & $x$ & & $x$ \\
\hline asset categories & & $x$ & & $\mathrm{x}$ & & $x$ \\
\hline educational categories & & $x$ & & $x$ & & $x$ \\
\hline per capita log expenditure & & $x$ & & $x$ & & $x$ \\
\hline$n$ & 931 & 931 & 1400 & 1400 & 1804 & 1804 \\
\hline
\end{tabular}

\begin{tabular}{|c|c|c|c|c|c|c|}
\hline & \multicolumn{2}{|c|}{ Rajasthan } & \multicolumn{2}{|c|}{ Uttar Pradesh } & \multicolumn{2}{|c|}{ West Bengal } \\
\hline & (7) & (8) & (9) & (10) & (11) & (12) \\
\hline \multirow[t]{2}{*}{ muslim } & $1.988^{*}$ & $1.731+$ & 0.927 & 0.856 & $3.002 * *$ & $1.650+$ \\
\hline & $(0.650)$ & (0.513) & $(0.186)$ & (0.183) & $(0.977)$ & $(0.495)$ \\
\hline \multirow[t]{2}{*}{ scheduled caste } & 0.967 & 0.853 & 1.370 & 1.256 & $1.589+$ & 0.914 \\
\hline & $(0.228)$ & $(0.201)$ & $(0.287)$ & $(0.266)$ & $(0.404)$ & $(0.244)$ \\
\hline female & $\mathrm{x}$ & $\mathrm{x}$ & $\mathrm{x}$ & $\mathrm{x}$ & $\mathrm{x}$ & $\mathrm{x}$ \\
\hline age dummies & $x$ & $x$ & $x$ & $x$ & $x$ & $x$ \\
\hline rural residence & & $x$ & & $x$ & & $x$ \\
\hline asset categories & & $x$ & & $x$ & & $x$ \\
\hline educational categories & & $\mathrm{x}$ & & $\mathrm{x}$ & & $\mathrm{x}$ \\
\hline per capita log expenditure & & $x$ & & $x$ & & $x$ \\
\hline$n$ & 1937 & 1937 & 2117 & 2117 & 1849 & 1849 \\
\hline
\end{tabular}

WHO SAGE, 2007-08. Exponentiated coefficients. Standard errors clustered at the level of the primary sampling unit in parentheses. $+\mathrm{p}<.1,{ }^{*} \mathrm{p}<.05,{ }^{* *} \mathrm{p}<.01,{ }^{* * *} \mathrm{p}<.001$. All regressions are weighed using national individual weights. 
Table A8: Comparison of adults in the SAGE's (2007-8) six state sample to adults in the nationally representative IHDS (2005)

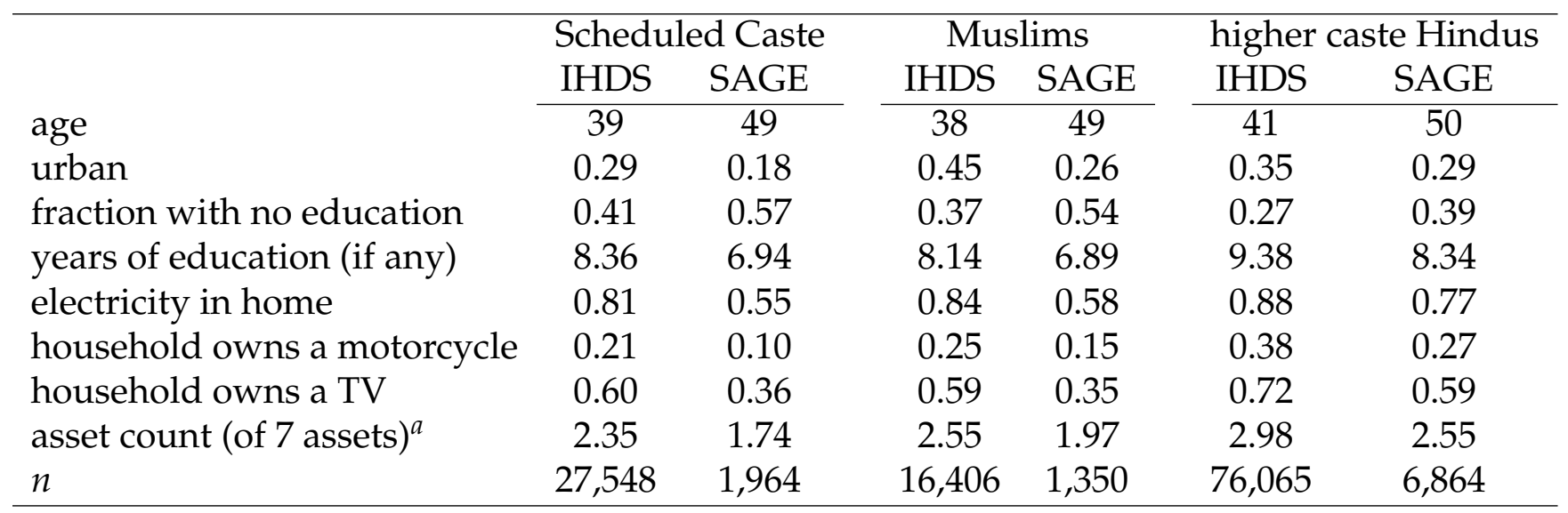

The table presents weighted summary statistics by population group for adults 18-85 from the WHO SAGE data and the India Human Development Survey (IHDS). ${ }^{a}$ The 7 assets, measured in both surveys, are a bicycle, a refrigerator, a motorcycle, a table or chair, a television, a computer, and a car. 
Figure A1: Mental health outcomes by measures of socioeconomic status and social group
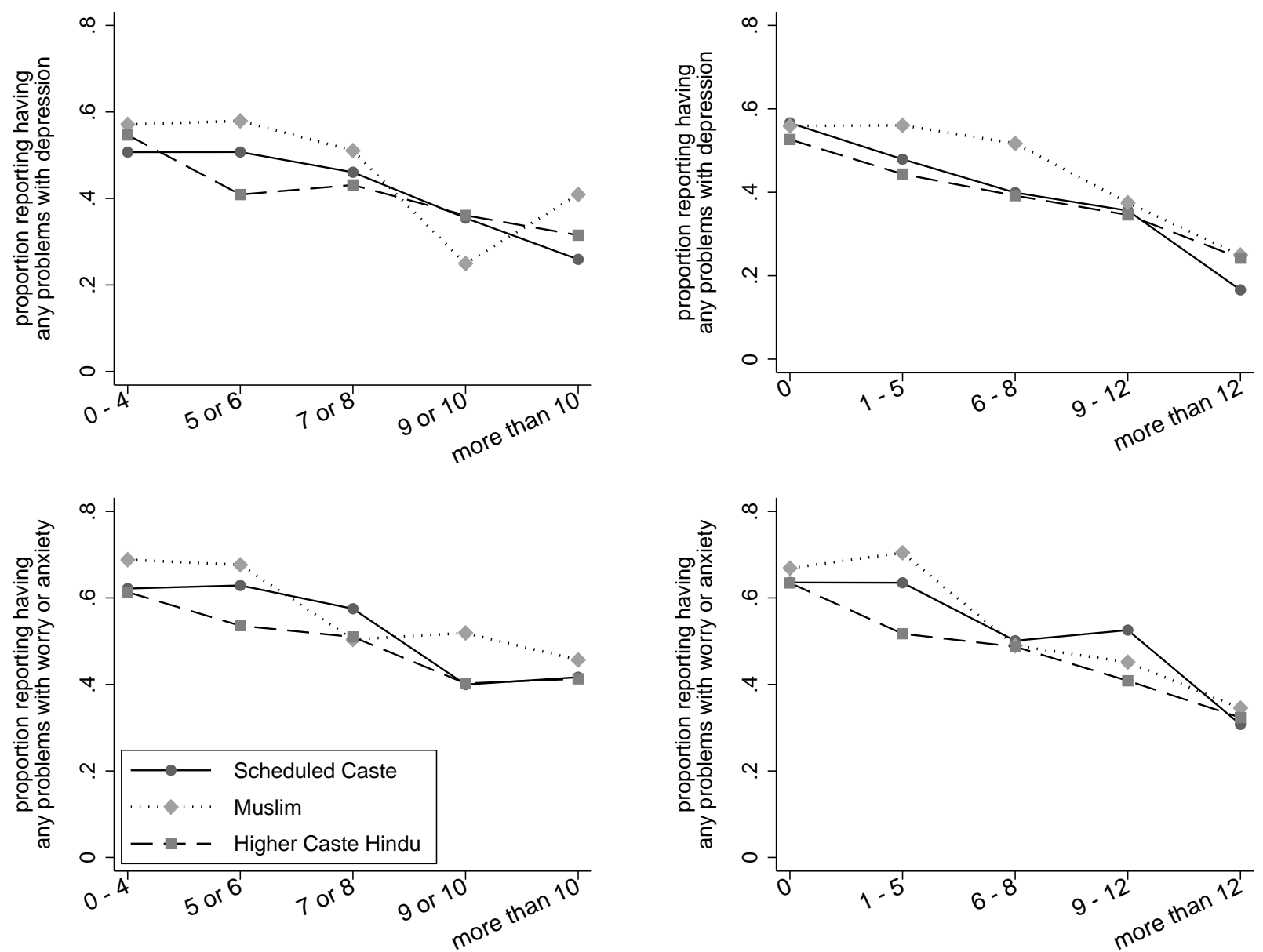

a) by number of assets owned

b) by years of education

WHO SAGE, 2007-08. 
Figure A2: Local polynomial regressions of mental health outcomes by age and social group
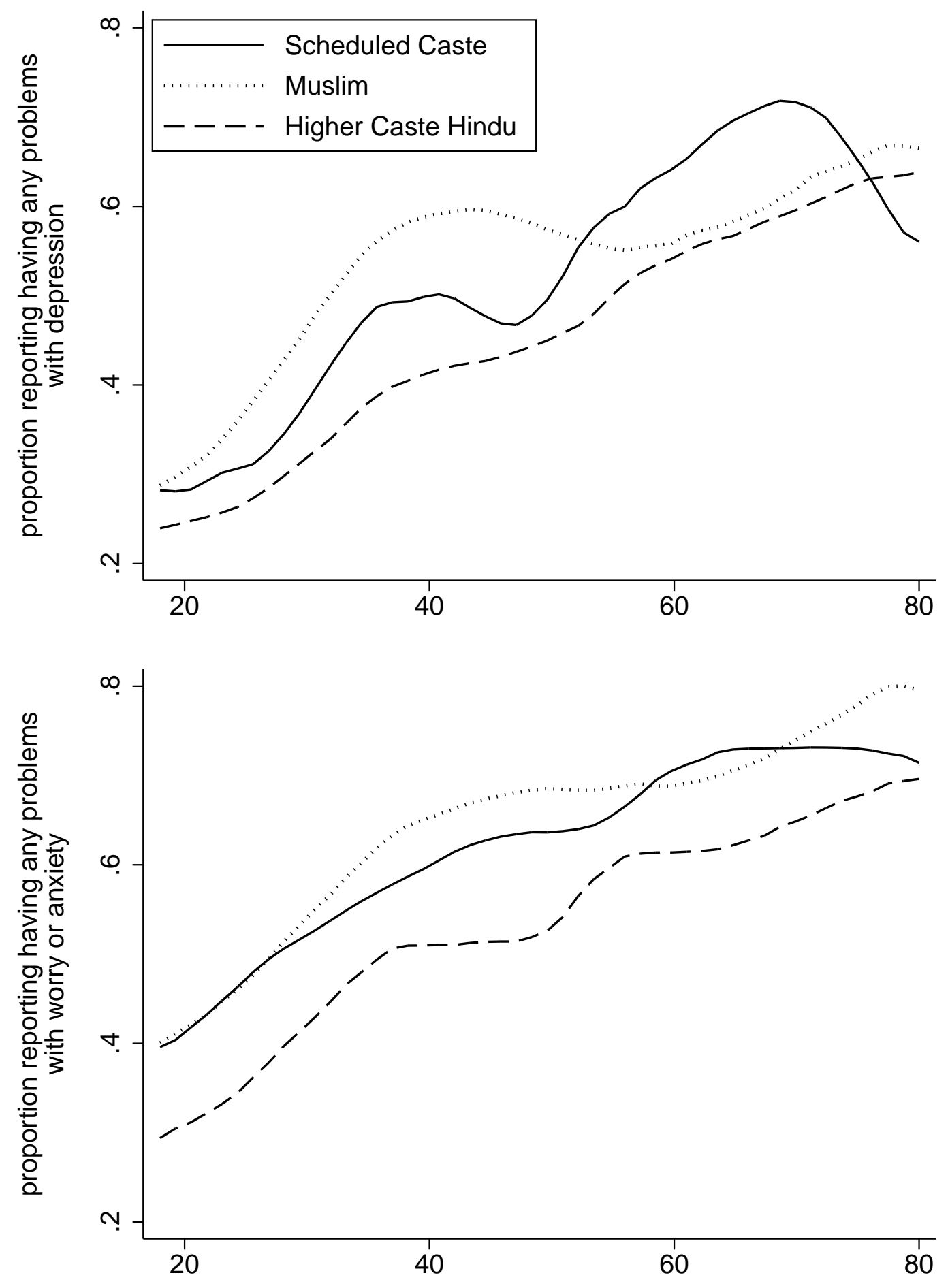

WHO SAGE, 2007-08. 
Figure A3: Mental health outcomes by sex and social group
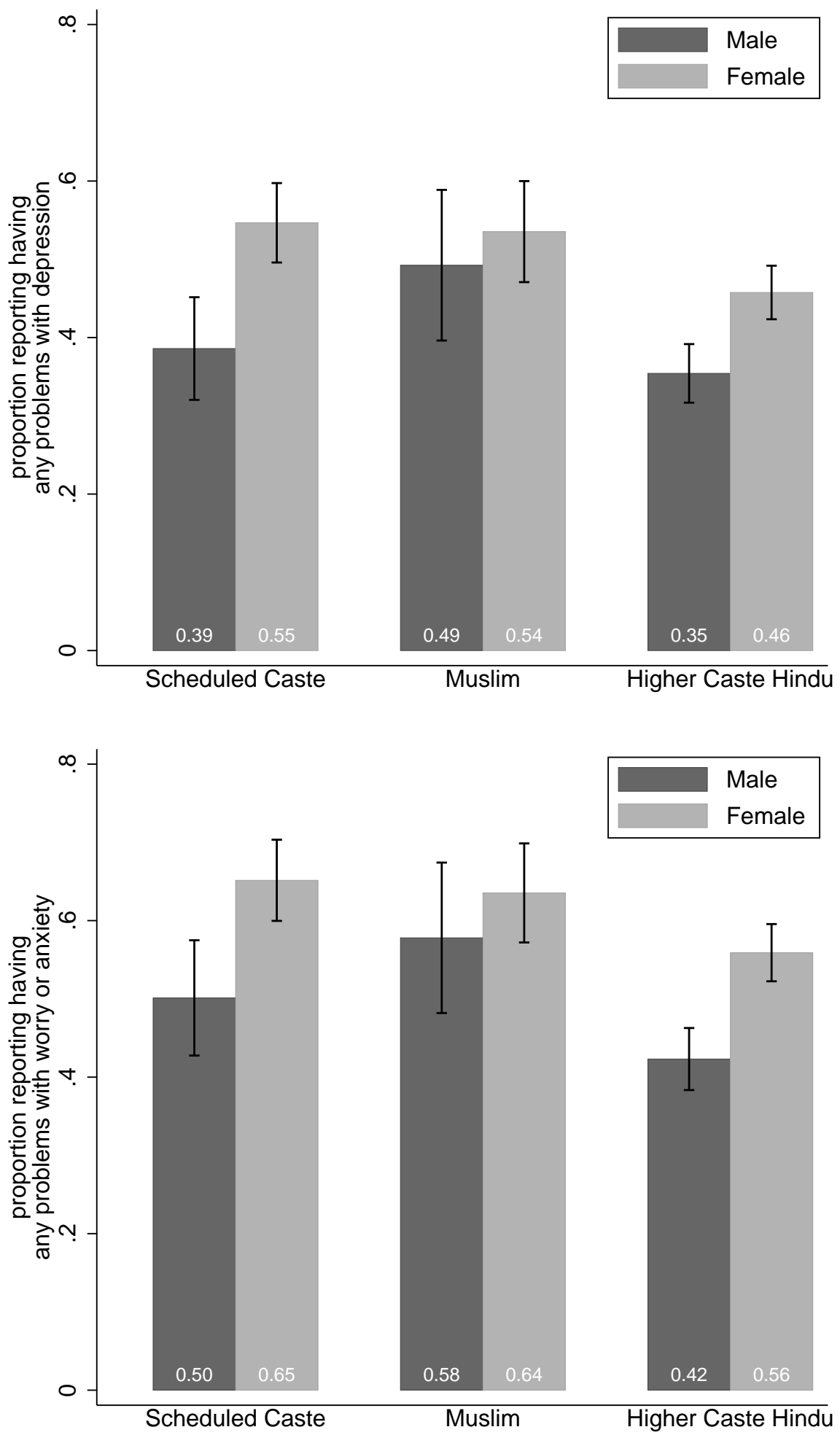

WHO SAGE, 2007-08. 